University of Wollongong

Research Online

Faculty of Engineering and Information

Faculty of Engineering and Information

Sciences - Papers: Part B

Sciences

2018

Compressive test of GFRP-recycled aggregate concrete-steel tubular long columns

Lan Zeng

University of Wollongong, Guangdong University of Technology

L J. Li

Guangdong University of Technology

Zhi Su

Keyland

Feng Liu

Guangdong University of Technology

Follow this and additional works at: https://ro.uow.edu.au/eispapers1

Part of the Engineering Commons, and the Science and Technology Studies Commons

Research Online is the open access institutional repository for the University of Wollongong. For further information contact the UOW Library: research-pubs@uow.edu.au 


\title{
Compressive test of GFRP-recycled aggregate concrete-steel tubular long columns
}

\begin{abstract}
In order to alleviate the problem of growing construction waste and utilize the favorable material properties of fibre-reinforced polymer (FRP), a novel form of composites, FRP-recycled aggregate concrete-steel columns (FRSCs), was proposed based on hybrid FRP-concrete-steel double-skin tubular columns (DSTCs). The composite of FRSC consists an outer FRP tube and an inner steel tube with an annular area of recycled aggregate concrete (RAC) filled between both tubes. To further investigate the compressive behavior of these composites, an experiment of Glass FRP-RAC-steel tubular long columns (FRSLCs) was performed subjected to monotonic axial compression. Three parameters were designed in the test, which are the recycled coarse aggregate (RCA) replacement ratio, the slenderness ratio and the cross-section loading method. The influence of these parameters was analyzed on the bearing capacity, lateral deflection performance and the load-strain relationship of FRSLCs. The test results show that FRSLCs have good bearing capacity and excellent ductility. Two models for DSTCs were transformed to apply in FRSLCs, which has found that Lu's model (2013) is appropriate to predict the ultimate bearing capacity of FRSLCs under the whole area loading.

\section{Disciplines}

Engineering | Science and Technology Studies

\section{Publication Details}

Zeng, L., Li, L., Su, Z. \& Liu, F. (2018). Compressive test of GFRP-recycled aggregate concrete-steel tubular long columns. Construction and Building Materials, 176 295-312.
\end{abstract}




\title{
Compressive test of GFRP-recycled aggregate concrete-steel
}

\section{tubular long columns}

\author{
Lan Zeng ${ }^{1,2}$, Lijuan $\mathrm{Li}^{1 *}$, Zhi Su${ }^{3}$, Feng Liu ${ }^{1}$ \\ ${ }^{1}$ : School of Civil and Transportation Engineering, Guangdong University of Technology, \\ Guangzhou 510006, China \\ 2: Faculty of Engineering and Information Sciences, University of Wollongong, NSW 2500, \\ Australia \\ ${ }^{3}$ : Keyland, Hangzhou 310003, China \\ *Corresponding author: lilj@gdut.edu.cn
}

\begin{abstract}
In order to alleviate the problem of growing construction waste and utilize the favorable material properties of fibre-reinforced polymer (FRP), a novel form of composites, FRP-recycled aggregate concrete-steel columns (FRSCs), was proposed based on hybrid FRP-concrete-steel double-skin tubular columns (DSTCs). The composite of FRSC consists an outer FRP tube and an inner steel tube with an annular area of recycled aggregate concrete (RAC) filled between both tubes. To further investigate the compressive behavior of these composites, an experiment of Glass FRP-RAC-steel tubular long columns (FRSLCs) was performed subjected to monotonic axial compression. Three parameters were designed in the test, which are the recycled coarse aggregate (RCA) replacement ratio, the slenderness ratio and the cross-section loading method. The influence of these parameters was analyzed on the bearing capacity, lateral deflection performance and the load-strain relationship of FRSLCs. The test results show that FRSLCs have good bearing capacity and excellent ductility. Two models for DSTCs were transformed to apply in FRSLCs, which has found that Lu's model (2013) is appropriate to predict the ultimate bearing capacity of FRSLCs under the whole area loading.
\end{abstract}

Keywords: glass fibre-reinforced polymer (GFRP); double-skin tubular column (DSTC); recycled aggregate concrete (RAC); long column; axial compression; ultimate bearing capacity 


\section{Introduction}

Past decades have witnessed millions of traditional steel structures facing the critical problem of rust which takes a severe toll on the bearing capacity of bridges and buildings, especially in the marine environment [1]. This also promotes a new type of construction materials, fibre-reinforced polymer (FRP), to apply on the field of civil engineering [2]. Since FRP has promising material properties of high strength, low weight and excellent corrosion resistance, FRP can exert a favorable effect on structure reinforcement or retrofit as an outer material wrapping the traditional ones [3, 4]. Moreover, various forms of FRP composites are developing rapidly [5-7], among which includes hybrid FRP-concrete-steel double-skin tubular columns (DSTCs) proposed by Teng et al. [8]. DSTCs with appropriate diameter-to-thickness ratios of the steel tubes have the following advantages compared with traditional concrete filled FRP tubes (CFTs). First, DSTCs are designed to be hollow-cored, which reduces the column weight without significantly affecting the flexural rigidity of the sections and allows the easy passage of service ducts. Second, the steel tubes in DSTCs can compensate the strength loss of hollow-cored concrete and help resist the lateral earthquake action. Also, the steel tubes in DSTCs can support construction loads as formworks, and the mature techniques of welding and assembly can be utilized for steel connection to beams, making construction safer and easier. Last, since the outer FRP tubes in DSTCs are taken as formworks during construction and as confining devices and additional shear reinforcement during earthquakes, it is not compulsive for DSTCs to do the fire protection [9-11].

Meanwhile, numerous tons of concrete waste from damaged buildings and constructions are left after a disaster of earthquake around the world every year [12], as well as the demolition of large majorities of inappropriate buildings, which not 
only makes trouble on the disposal of mountains of concrete waste, but also occupies lots of farming lands. In fact, wasted concrete can be reused into brand-new buildings after a process of special treatment $[13,14]$. This recycled aggregate concrete (RAC) contains recycled coarse aggregate (RCA) which can replace natural coarse aggregate (NCA) partially or wholly. Even though compared with NAC, RAC has several faults $[15,16]$, such as high porosity and water absorption, there is still one of the most obvious merits of RAC that is better ductility [17]. It is thrilling to make structures with high seismic performance by using abolished materials left from earthquakes. As a result, to take both advantages of DSTCs and RAC, a composite of FRP-RAC-steel columns (FRSCs), replacing NAC in DSTCs with RAC, was proposed by the second author of this paper [18]. The composite consists of an outer FRP tube, an inner steel tube and an annular RAC between both tubes. The shape of both tubes can be rectangular or circular, and the inner tube can be central or eccentric.

These proposed novel composites, FRSCs, are expected to inherit most merits of DSTCs which fully exploit the advanced mechanical properties of every component of the composites. Furthermore, FRSCs help alleviate the environmental pollution caused by demolished concrete, realizing the sustainable development of natural resources. FRSCs also help upgrade the application level and develop the application area of RAC to provide an alternatively environmentally friendly structural composite. Since the proportion and the width of RAC in this column are relatively small, the shrinkage and creeps of RAC may have less effect on the long-term performance of FRSCs. Moreover, the inner steel tube is expected to burden a large proportion of axial loading and to help restrict the lateral dilation of RAC. Also, the coverage of FRP can protect the RAC from environmental corrosion to improve its long-term performance $[19,20]$. Thus, in a combination with FRP and steel tubes, the negative 
impacts of RAC material deterioration are expected to decrease in the application of FRSCs. FRSCs are highly desirable for use as piers in bridges, piles, towers, or other load-bearing components of building structures in seismic regions or hostile environments [21]. As to piers, piles or towers, the connection problems on FRSCs are not significant. However, as to frame columns, the inner steel tubes in FRSCs can be connected to the steel beams or steel bars in reinforced concrete beams by welding, and the beam-column joints should be reinforced by steel rings or plates [22].

Research on this novel type of composites has just commenced, and very few studies take FRSCs as their subjects [23]. Most existing studies have focused on the axial compressive behavior of its stub columns but the long columns [24-28]. However, long columns are wildly used in project practice, and the slenderness ratio plays an important role on the axial compressive performance of long columns. It is also noted that contrasted to stub columns, the strains of long columns are heterogeneous at the same cross-section. Also, there is a second-order moment and corresponding deflection for long columns, which makes long columns fractured by bending or instability besides compression [29, 30]. Moreover, at long-term service, the creep of concrete will enlarge the lateral deflection of long columns [31], leading to a further decrease in bearing capacity of the structures. As to the theoretical study, since the concept of DSTCs was proposed, the research related to their constitutive models and calculations of the ultimate stress and strain has been mainly based on the test subjects of CFTs and double-skin tubular stub columns (DSTSCs) [32-36]. The calculation of the ultimate bearing capacity of double-skin tubular long columns (DSTLCs) is put forward considering the reduced factor of the slenderness ratio according to the studies on DSTSCs [37]. Recently the ultimate bearing capability calculations have been transformed to be briefer by introducing some rational 
assumptions and the analytic method of curvature [38, 39].

In order to testify the feasibility of RAC applying in DSTCs and to further promote this new type of composites in practical projects, the mechanical properties of FRSCs should be fully understood. Since the axial compressive behavior of the long columns may be greatly different from that of the short ones, axial compressive tests of FRP-recycled aggregate concrete-steel tubular long columns (FRSLCs) were conducted in order to understand the axial compressive behavior of FRSLCs and to check whether the existing ultimate bearing capacity calculations for DSTLCs are still suitable for FRSLCs.

\section{Experimental program}

\subsection{Specimen design}

A total of 12 FRSLC specimens were prepared and tested under monotonic concentric compression. The outer tube of each specimen was chosen a fabricated glass FRP (GFRP) tube with an inner diameter of $200 \mathrm{~mm}$ and a thickness of $4 \mathrm{~mm}$, and the inner tube of each specimen was chosen a seamless steel tube graded Q345 with an outer diameter of $121 \mathrm{~mm}$ and a thickness of $5 \mathrm{~mm}$. The space between both tubes was filled with RAC graded C40. The dimensional sketches of specimens were shown in Fig. 1.

To investigate the influence of parameters on the axial compressive performance of FRSLCs, three parameters were designed in the tests, which included five RCA replacement ratios $(0,30 \%, 50 \%, 70 \%$ and $100 \%)$, three slenderness ratios $(15.3,20.4$ and 25.5) with different heights of specimens (900 mm, $1200 \mathrm{~mm}$ and $1500 \mathrm{~mm})$ correspondingly, and two loading methods that were the whole cross-section area of loading and the core cross-section area of loading. The method of core cross-section area loading meant the axial compression was performed on the steel tube and RAC 
without the FRP tube in order to investigate the effect of FRP confinement. The specimens with a same RCA replacement ratio were cast in the same batch, comprising three standard RAC cubes $(150 \mathrm{~mm} \times 150 \mathrm{~mm} \times 150 \mathrm{~mm})$ and three RAC cylinders $(\Phi 150 \mathrm{~mm} \times 300 \mathrm{~mm})$ for each $\mathrm{RCA}$ replacement ratio to test the RAC material properties. The design of each specimen was listed in Table 1.

\subsection{Test materials}

According to the standards of ASTM A501/A501M-14 [40] and ISO 6892-1: 2016 [41], three test coupons were cut and shaped from the same long steel tube that was used in the composite specimens. The tensile test of the steel coupons was performed on an electronic universal testing machine Type DDL300 produced in Changchun research institute for mechanical science Co. Ltd. The tensile test of steel coupons was shown in Fig. 2, and the main properties of steel tubes were summarized in Table 2. Based on the recording from the vertical strain gauges attached in the middle of both sides of the steel coupons, the stress-strain relationship of steel tubes was shown in Fig. 3. From the first segment of the stress-strain curve of steel tubes, the elastic modulus was calculated, and from the second segment of the stress-strain curve after the steel yielding, the steel strength still developed gradually.

Prefabricated GFRP tubes were chosen in the test, which were manufactured in Guangdong Sunny FRP Co. Ltd by filament winding that includes $40 \%$ of glass fibre spirals in a degree of 80 and proportion of epoxy resin matrix. According to the standard of ASTM D2290-16 [42], the split-disk test of GFRP rings was performed on the electronic universal testing machine Type DDL300, as shown in Fig. 4. The split disk with an outer diameter of $300 \mathrm{~mm}$ was designed to connect with the testing machine. Three GFRP rings with a height of $30 \mathrm{~mm}$ were cut from the same long GFRP tube that was used in the test composite specimens after flatting both ends of 
the ring. Two groups of strain gauges with a hoop one and an axial one were set on the surface of the GFRP ring at an angle of 0 and 180, respectively. The main properties of GFRP tubes from the average values of the three test rings were summarized in Table 3.

According to the standards of ASTM C39/C39M-18 [43] and ASTM C469/C469M-14 [44], the concrete with an average compressive strength of $40 \mathrm{MPa}$ based on the standard concrete cubes was designed and prepared in the laboratory. The concrete mixture proportions of five batches of concrete were listed in Table 4 . Each batch of concrete had the same water-cement ratio of 0.49 and sand ratio of 0.45 , and NCA was replaced by RCA on the basis of its volume.

Ordinary Portland cement with early consolidation and an average compressive strength of $42.5 \mathrm{MPa}$ based on the cement mortar prisms $(40 \mathrm{~mm} \times 40 \mathrm{~mm} \times 160 \mathrm{~mm})$ [45] was applied, and tap water met the criteria of residential water was used to cast the concrete. Normal river sand with a fineness modulus of 2.65 was used as the fine aggregate. Since the gap between the FRP tube and the steel tube of the specimen is so narrow, the coarse aggregate with particle sizes ranged from $5 \mathrm{~mm}$ to $10 \mathrm{~mm}$ was sieved and used to ensure the quality of concrete casting. NCA was granite gravel with an apparent density of $2556 \mathrm{~kg} / \mathrm{m}^{3}$, and RCA with an apparent density of 2246 $\mathrm{kg} / \mathrm{m}^{3}$ was provided by Shenzhen Lvfar Pengcheng Green Technology Co., Ltd. as industrial products. Both coarse aggregates were isolated in the sun for $48 \mathrm{~h}$ to ensure the moisture content down to zero before the casting. To reduce the negative influence of high water absorption for RCA, additional water of $6.3 \%$ based on the mass of RCA was supplemented.

The compressive strengths of concrete cubes and cylinders, as well as their slumps and elastic moduli were also listed in Table 4. The slump and the elastic modulus of 
RAC decline with an increase in the RCA replacement ratio, which may result from the high porosity and water absorption of RCA. The compressive strength of RAC does not generally decrease with an increase in the RCA replacement ratio. On the contrary, the tendency of the compressive strength is on the increase. This is likely due to the good conditions of RCA which was derived from high-rise buildings with high-strength concrete [46]. Moreover, the strength development of RAC in the late period is faster than that of NAC if full hydration state is reached, which indicates that the pore geometry of RAC plays a critical role in the concrete strength [47].

\subsection{Specimen preparation}

The preparation of FRSLC specimens included the following steps. Firstly, the steel tube was welded on a smooth square steel plate as a baseboard with a side length of $300 \mathrm{~mm}$ and a thickness of $20 \mathrm{~mm}$. The steel tube was vertical to the steel plate, and both centers coincided. Then the strain gauges were attached to the surface of the steel tube after removing its rust by a grinding wheel. The surface of the strain gauges was covered with a layer of waterproof sealant to prevent the cement grout into strain gauges and to ensure the insulation between the steel tube and electric wires. Also, one more layer of epoxy resin was covered outside the sealant to prevent the aggregate crashing strain gauges. Secondly, the GFRP tube and the steel tube should be centralized. The bottom end of the GFRP tube was positioned by four steel blocks welded on the steel baseboard and fixed by a ring of glass cement in order to avoid cement grout leakage; the top end of the GFRP tube was restricted by a wooden cross attached four blocks with a width equaling to the gap space of both tubes, as shown in

Fig. 5. Three tiny holes were drilled $10 \mathrm{~mm}$ below the top edge of the GFRP tube to pass the electronic wires connected to the strain gauges of the steel tube. As to the FRSLC specimens designed for the core area loading, since the outer GFRP tube was 
not burdened the axial compression directly, a removable GFRP ring with a width of $10 \mathrm{~mm}$ was arranged on the top to the GFRP tube, and the GFRP ring would be removed after concrete casting and final setting. Thirdly, the concrete prepared based on the designed mixture proportions was cast into the annular space of both tubes. Since the annular space between two tubes was long and narrow, the concrete was cast in three segments for concrete quality guaranteeing. At last, the specimens were cured for more than 28 days before loading. The strain gauges were attached to the surface of the GFRP tube, and the top end of the specimens was leveled by high-strength gypsum before loading.

\subsection{Test set-up and measurements}

The monotonic compression test for FRSLCs was operated on an electro-hydraulic servo pressure machine Type YAW-10000F with a maximum load of $10000 \mathrm{kN}$. The whole loading process was controlled by equal displacement at a loading rate of 0.36 $\mathrm{mm} / \mathrm{min}$ to obtain continuous measurements. All test data were recorded simultaneously by a data logger DTS530 produced in Tokyo Sokki Kenkyujo Co., Ltd. The test set-up and its loading process were shown in Fig. 6. The load was exerted from the crossbeam of the pressure machine and passed on the upper plate to make sure that the load was applied on the specimen evenly. The load stopped until the GFRP tube fractured and the bearing capacity dropped dramatically below to $80 \%$ of the peak bearing capacity of the specimen.

In order to measure the deformation and displacement, some strain gauges and linear variable displacement transducers (LVDTs) were arranged on the surface of GFRP tubes and steel tubes, as shown in Fig. 7. For the steel tube, two bi-directional strain rosettes with a gauge length of $10 \mathrm{~mm}$ were set evenly at the mid-height of its outer surface. For the GFRP tube, three bi-directional strain rosettes with a gauge 
length of $20 \mathrm{~mm}$ were set at an equal distance at three cross-sections of its outer surface. Those three cross-sections (Section A, B and C) were distributed at the $1 / 4$, $1 / 2$ and $3 / 4$ of the total height of the specimen from the bottom to top, and a horizontal LVDT with a maximum of $200 \mathrm{~mm}$ was set in each section, as well as an additional horizontal LVDT with a maximum of $200 \mathrm{~mm}$ at Section B on the opposite side. Moreover, a vertical LVDT with a maximum of $200 \mathrm{~mm}$ was installed at the top of the specimen in order to measure the shortening of the specimen during the test.

\section{Test result and discussion}

\subsection{Failure modes}

The failure modes of each specimen were basically similar, as shown in Fig. 8. The specimen burdened axial compression and bending moment at the same time so that both axial shortening and lateral deformation revealed on it during the whole process of loading. At the first period of loading, the specimen was in the elastic stage that the bearing capacity increased rapidly and the lateral deflection was relatively small. When the load increased to $50-60 \%$ of its ultimate bearing capacity, the bearing capacity of the specimen increased more slowly while its lateral defection began to develop obviously. Several slight white cracks were shown in the middle region of the surface of the GFRP tube. Moreover, the cracks developed dramatically and expanded to an area. With the load increasing before the failure of the specimen, obvious circumferential and diagonal cracks could be seen on the surface of the GFRP tube, accompanying with intermittent sounds of fibre tearing. At the moment of the load reaching the ultimate bearing capacity of the specimen, with a loud explosive sound, the top end of the GFRP tube was stripped destructively, and the exposed concrete was crushed. The bearing capacity of the specimen declined sharply, and the lateral deflection continued to increase. Soon after that, the specimen was unable to burden 
loads anymore. However, there was no obvious buckling in the inner steel tube, which showed an effective constraint on the concrete during the whole loading process.

However, the failure modes of specimens with three test parameters slightly display their own features. Compared with the situation under the whole area loading, the top end of concrete is crushed more seriously and the top GFRP tube is splintered more obviously under the core area loading. Moreover, the lateral deflection of the specimen under the core area loading is smaller and its crack area of the FRP tube is also larger. With an increase in the RCA replacement ratio, the cracks of the GFRP tube are thinner and shallower, but their distribution areas are larger and the failure of the top GFRP tube is more obviously. With an increase in the slenderness ratio, the lateral deflection of the specimen increases greatly and the diagonal cracks of the GFRP tube increases, but its circumferential cracks decline. It should be pointed out that one part of the head of Specimen Co-100-1200 destroyed seriously, which may result from the deviations of operation and manipulation that led to testing installation a little eccentrically. Thus the test results of this specimen may not be as coincident as its facts.

\subsection{Bearing capacity}

The bearing capacity and mid-span deflection of FRSLCs were listed in Table 5. $P_{k}$ refers the peak bearing capacity of the specimen; $P_{c o}$ is the bearing capacity of unconfined concrete, which is calculated via the strength of the corresponding concrete cylinder multiplying the annular area of concrete in the specimen; and $\delta_{k}$ and $\delta_{\max }$ are the mid-span deflections of the specimen corresponding to its peak bearing capacity and rupture bearing capacity, respectively.

From the ratio of $\delta_{\max }$ to $\delta_{k}$ in Table 5, the increase values of mid-span deflection of specimens from the peak bearing capacity to rupture bearing capacity are basically 
less than $10 \%$, which mainly results from the unbuckling steel tubes and the continued development of GFRP confinement after the specimen fracture. Even the outer GFRP tube is full of cracks because of the expanding concrete, the GFRP tube together with the steel tube still maintains a form of integrality so that two tubes can constrain the concrete effectively from large lateral deformation and keep the specimen stable after its rupture. It is estimated that the bearing capacity of the specimen will increase greatly if the outer GFRP tube reinforced appropriately.

The influences of three test parameters on the peak bearing capacity of specimens are considered in the experiment, as shown in Figs. 9-11. As to the influence of the RCA replacement ratio in Fig. 9, with the same slenderness ratio, the peak bearing capacity of RAC composites under the whole area loading increases by $10-20 \%$ compared to that of NAC composite (Specimen Cw-0-1200). One of the obvious reasons is that the bearing capacity of the specimen is influenced by the strength of RAC which is further affected by RCA. The other reason is that the surface of RCA is relatively rough so that it has reliable adhesion with other components of RAC to decrease the slip of two tubes and increase the confinement effect. Among different RCA replacement ratios, the peak bearing capacity of specimens tends to improve with an increase in the RCA replacement ratio. However, the improvement of specimens with RCA replacement ratios of 70\% and 100\% (Specimens Cw-70-1200 and Cw-100-1200) is not obvious as that with other two ratios (Specimens Cw-30-1200 and Cw-50-1200). This is partly because RCA accumulates numerous micro-cracks from its former usage and treatment that decrease the strength of RAC. Meanwhile, the surface of RCA is covered with old and loose mortar, which makes the interfacial transition zone of old mortar and new mortar weaker in adhesion. Since the variety and complexity of RAC, the bearing capacity of its composites is also 
fluctuant. As to the situation of core area loading, the influence of RCA replacement ratio is more apparent. Compared with that of NAC composite (Specimen Co-0-1200), the peak bearing capacity of the specimen with an RCA replacement ratio of $50 \%$ (Specimen Co-50-1200) increases by $28.8 \%$, and that of the specimen with an RCA replacement ratio of $100 \%$ (Specimen Co-100-1200) decreases by $17.4 \%$. Thus, compared with the NAC composites, the bearing capacity of specimens with lower RCA replacement ratios improves more obviously than that with higher ratios.

Figure 10 shows the influence of slenderness ratios on the peak bearing capacity of specimens. On the same condition of the RCA replacement ratio and loading method, with an increase in the slenderness ratio, the peak bearing capacity of specimens under the whole area loading increases to some extent. Compared to that of the specimen with a slenderness ratio of 15.3 (Specimen Cw-100-900), the peak bearing capacity of the specimens with slenderness ratios of 20.4 and 25.5 (Specimens $\mathrm{Cw}-100-1200$ and $\mathrm{Cw}-100-1500)$ increases by $15 \%$ and $1.7 \%$, respectively. However, when it comes to the core area loading, compared with that of the specimen with a slenderness ratio of 15.3 (Specimen Co-100-900), the peak bearing capacity of the specimens with slenderness ratios of 20.4 and 25.5 (Specimens Co-100-1200 and Co-100-1500) decreases by $26.8 \%$ and $2.3 \%$, respectively. From the improvement of bearing capacity of Specimen Cw-100-1200, it is noted that the favorable confinement effect of GFRP tube can greatly compensate the negative effect of the slenderness ratio on bearing capacity of specimens.

Figure 11 shows the influence of loading methods on the peak bearing capacity of specimens. Under the same condition of the slenderness ratio and the RCA replacement ratio, the peak bearing capacity of specimens under the core area loading basically decreases by approximately $10 \%$ than that of specimens under the whole 
area loading. There are two main reasons to explain this decline: compared with those under the whole area loading, the specimens under the core area loading develop more rapidly in axial shortening of the inner steel tube, which makes the slip steel tube can no longer work together with RAC and accelerates the cracks of concrete from ends to the middle region; furthermore, the constraint effect of both tubes deteriorates seriously because of the crushing concrete, which leads to the bearing capacity of specimens under the core area loading declining further.

\subsection{Lateral deformation}

\subsubsection{Load - mid-span deflection relationship}

The curves of load - mid-span deflection of specimens are shown in Fig. 12. With the load increases, the mid-span deflection of specimens enlarges. The load - mid-span deflection curves can be generally divided into two segments. In the first segment, the load increases sharply with little increase in the mid-span deflection, which reveals a relatively large slope of the curve. However, in the second segment, the mid-span deflection increases obviously with little increase in the load, which reveals a relatively small slope of the curve. The second segment of the curve has a steady extension, which means the specimen has good ductility performance approaching its fracture.

The influence of the RCA replacement ratio on the load - mid-span deflection relationship can be seen in Fig. 12(a)-(b). Compared with those of NAC composites, the second segments of RAC composites extend steadily, which means the mid-span deflection of RAC composites increases obviously with the development of their bearing capacity at the later stage. Also, the load - mid-span deflection curves of RAC composites (Specimens Cw-50-1200 and Cw-70-1200) decrease slowly after reaching the peak bearing capacity, which indicates better ductility. The initial stiffness of RAC 
composites is basically larger than that of NAC composites under the whole area loading, and the initial stiffness of specimens with different RCA replacement ratios varies, which may result from the elastic modulus of RAC in the composites. The initial stiffness and ultimate mid-span deflection of specimens with different RCA replacement ratios are more variable under the core area loading, which reflects that the loading method has an effect on the steel tube constraint even before the FRP tube confinement exerting.

The influence of the slenderness ratio on the load - mid-span deflection relationship can be seen in Fig. 12(c)-(d). The load - mid-span deflection curves of specimens with a smaller slenderness ratio (Specimens Cw-100-900 and Co-100-900) tends to be linear with a sharp increase in bearing capacity but a very limited increase in deflection during the whole loading period. However, the mid-span deflection of the specimens with larger slenderness ratios increases obviously with a long extension of the second segment. All specimens with different slenderness ratios have similar initial stiffness, which indicates that the initial stiffness is less influenced by the slenderness ratio of specimens.

The influence of two loading methods on the load - mid-span deflection relationship can be seen in Fig. 12(e)-(f). Compared with that of the core area loading, the mid-span deflection and the peak bearing capacity of specimens under the whole area loading are generally larger with long bullish curves. However, the initial stiffness of specimens with different loading methods is various, which reflects that FRP tubes have not played a critical role at the first stage of loading. This also indicates the complex force mechanism of these composites. The specimens with a favorable constraint of two tubes have a good mechanical performance, while those with an unreliable constraint of two tubes and premature crushing RAC show 
apparent brittleness.

\subsubsection{Lateral deflections at three cross-sections}

Figure 13 shows the lateral deflection which was measured by three LVDTs at three cross-sections along the height of the specimen under different loads. The lateral deflection is small at the early stage of loading, especially before the load reaching $0.6 P_{k}$. With the load increasing, the lateral deflection at three cross-sections increases rapidly but at different rates. The mid-span deflection is not only larger, but also increases more rapidly than the other lateral deflection at both sides of the specimen. As a result, the lateral deflection at two sides has an axisymmetric tendency based on the middle span, especially at the later stage of loading where the curve of the height-lateral deflection at different cross-sections of the specimen resembles half waves of a sinusoid.

The lateral deflection at various cross-sections of the specimen with three test parameters has some individual features. From Fig. 13(a)-(c), with an increase in the RCA replacement ratio, the lateral deflection increases more obviously, even in the early period of loading, which has relations with the ductility of RAC. As to the influence of the slenderness ratio shown in Fig. 13(a), (d) and (e), the deflection with a larger slenderness ratio develops more rapidly than that with a smaller slenderness ratio, which reflects on the mid-span deflection most. At the later stage of loading, the axisymmetric tendency for the specimen with a higher slenderness ratio (Specimen $\mathrm{Cw}-100-1500)$ is very obvious. However, the mid-span deflection of the specimen with a lower slenderness ratio (Specimen $\mathrm{Cw}-100-900)$ is similar to or even smaller than the lateral deflection at both sides at the early stage of loading. As to the influence of the loading method shown in Fig. 13(a) and (f), compared with that of the specimen under the whole area loading (Specimen Cw-0-1200), the initial lateral 
deflection of the specimen under the core area loading (Specimen Co-0-1200) is smaller but more unstable that is easy to have deflection towards a different direction. As the load increases, the later lateral deflection of specimens under the core area loading increases rapidly even larger than that of specimens under the whole area loading.

\subsection{Axial strain in GFRP tube at cross-sections}

The distribution of axial strains in GFRP tubes at cross-sections under different loads is shown in Fig.14. At the beginning of the loading, the axial strains at the measure points of each cross-section are similar and relatively small. With the loads increasing, the axial strains in GFRP tubes at each cross-section increase in both speed and amplitude. It can be noted that the strains around the cross-section develop at the same pace with an increase in loading, which obeys the plane cross-section assumption. The axial strains at one side of the GFRP tube develop dramatically during the late loading period. From Fig. 14(a)-(d), the axial strains at the middle region of the column (Section B) are smaller than those at the end of the column (Section C). However, the tendency of the strain development is the same in each section, which also coincides with the plane cross-section assumption. From Fig. 14(c)-(f), the axial strains of specimens with a larger slenderness ratio is even smaller than those with a lower slenderness ratio.

\subsection{Load-strain relationship}

\subsubsection{Curves of load - mid-span strain in GFRP tubes}

The curves of load - mid-span strain in GFRP tubes are shown in Fig. 15. Axial strains and hoop strains are the average values correspondingly collected from the axial strain gauges and hoop strain gauges in the middle of the FRP tube. The curves of load mid-span strain in GFRP tubes can be regarded into two segments. The first segment 
of the curve has a larger slope with an obvious development of bearing capability, while the second one has a smaller slope with an obvious development of deformation. The hoop strain and the axial strain for the same specimen have a similar tendency of development, and both curves of load-axial strain and load-hoop strain have the inflection point between two segments of each curve under nearly the same load.

From Fig. 15(a)-(b), the influence of the RCA replacement ratio on the relationship of loads and mid-span strains in GFRP tubes can be seen. Compared with NAC composites, RAC composites generally have slightly larger initial stiffness and longer second segments with larger slopes, which indicates that their FRP confinement effect is better. Among various RCA replacement ratios for RAC composites, their slopes of load - mid-span strain curves are similar, especially for the specimens under the whole area loading, which means that the RCA replacement ratio has little effect on the second stiffness of GFRP tubes. Moreover, for the specimens under the core area loading, the inflection points of the load - mid-span strain curves with different RCA replacement ratio appear under different loads, which mainly results from the early crushed RAC that advances the confinement of the outer GFRP tube to take into effect.

The influence of the slenderness ratio on the curves of load - mid-span strain in GFRP tubes can be shown in Fig. 15(c)-(d). Compared to those with larger slenderness ratios, the specimens with smaller slenderness ratios has a larger slope of the load - mid-span strain curves, which means their initial stiffness is larger. Furthermore, both axial strains and hoop strains of the specimens with smaller slenderness ratio increase less with an increase in loads, even a downward tendency of strains appears in Specimen $\mathrm{Cw}-100-900$. This may result from the premature crushing RAC that weakens the confinement effect of the GFRP tube. However, since 
both tubes are still exerting the constraint effect, the bearing capacity of the specimen can increase. Under the whole area loading, specimens with various slenderness ratios have almost the same bearing capacity at the inflection points before the second nonlinear segment whose slopes are similar. In contrast, under the core area loading, specimens with smaller slenderness ratios have the load - mid-span strain curves with a short but larger slope of the second segment, which means their ductility has not fully played and the slenderness ratio has a relatively obvious influence on the second stiffness of specimens under the core area loading.

The influence of the loading method on the load - mid-span strain curves can be seen from the two groups of specimens in Fig. 15(e)-(f). Compared with those under the core area loading, the bearing capacity and strains of GFRP tubes develop more adequately under the whole area loading with a longer and larger slope of the second segment. However, since the specimens with smaller slenderness ratios have a relatively larger axial stiffness, the stiffness increment under the whole area loading is not as obvious as those with larger slenderness ratios. Moreover, the axial compression of the FRP tube under the whole area loading may even obstruct the effect of FRP hoop constraint. In other words, the contribution of the outer GFRP tube on the axial stiffness of the specimen is relatively small. Thus, the stiffness effect of the GFRP tube can be better performed on specimens with larger slenderness ratios.

\subsubsection{Curves of load - mid-span strain in steel tubes}

The curves of load - mid-span strain in steel tubes are shown in Fig. 16. The axial strain and the hoop strain are the corresponding average values of axial and hoop strain gauges at the middle span of the steel tube. The curves of load - mid-span axial strain in steel tubes tend to be divided into two segments, while those of load mid-span hoop strain in steel tubes have a tendency of three segments. The load - 
mid-span hoop strain curve has a short second segment whose slope is smaller and whose initial load is lower compared with the load - mid-span axial strain curve. Compared with the second segment of the load - mid-span hoop strain curve that is nearly flat, its third segment has a larger slope with an obvious increase in bearing capacity. However, both slopes of the second and third segments are smaller than that of the first segment. Generally, the steel tube begins to yield at the first inflection point of the load - mid-span hoop strain curve, and then its curve obeys the ideal elastoplastic model, and the GFRP tube begins to exploit the confinement effect at the second inflection point of the load - mid-span hoop strain curve where the load is similar with that at the first inflection point of the load - mid-span axial strain curve.

From Fig. 16(a)-(b), the influence of RCA replacement ratios on the curves of load - mid-span strain in steel tubes can be analyzed. The first segments of specimens with different RCA replacement ratios are nearly overlapped, which means the RCA replacement ratio has little influence on the initial stiffness of steel tubes. Also, the first inflection points of the load - mid-span hoop strain curves are around the same load of $1500 \mathrm{kN}$, which means the RCA replacement also has little influence on the steel yielding. However, as loads increase, with the fluctuation of the RCA replacement ratio, the distribution of the inflection point and the slope of the nonlinear segments also change. Moreover, the variety is more obvious for the curves of load mid-span axial strain than those of load - mid-span hoop strain, and it is more obvious for the curves of specimens under the core area loading than those under the whole area loading. As to the specimens under the whole area loading, the hoop stiffness of the steel tubes for specimens with lower RCA replacement ratios of RAC (Specimens Cw-0-1200 and Cw-30-1200) decreases at the later loading stage, which results from the premature crushing RAC with relatively large elastic moduli to weaken the 
constraint effect of the steel tubes. As to the specimens under the core area loading, compared to the specimen with a higher RCA replacement ratio (Specimen Co-100-1200), the first inflection points of Specimens Co-0-1200 and Co-50-1200 appear later, which means the yielding of their steel tubes is postponed and the material capability of their steel tubes exerts well. When the core RAC is crushed at the later stage of loading, the interaction of RAC and the steel tube decreases until the deformation of the steel tube is large enough to work together with the core RAC, after which the bearing capability of the specimen increases.

The influence of different slenderness ratios on the curves of load - mid-span strain in steel tubes is shown in Fig. 16(c)-(d). Under the whole area loading, the load mid-span strain curves are similar, which indicates that the slenderness ratio has little influence on both axial and hoop stiffness of steel tubes. However, under the core area of loading, the slopes of the second segments for specimens change with different slenderness ratios, which means that the slenderness ratio has a relatively obvious influence on the second stiffness of steel tubes. The second stiffness of the steel tube for the specimen with a smaller slenderness ratio (Specimen Co-100-900) develops more obvious than that with a larger slenderness ratio.

The influence of two loading methods on the curves of load - mid-span strain in steel tubes is shown in Fig. 16(e)-(f). Their tendency is similar with that of the curves of load - mid-span strain in GFRP tubes. The loading method has little influence on the initial stiffness of steel tubes. The way of whole area loading can increase the second stiffness of steel tubes for the specimens with larger slenderness ratios more dramatically compared to that for the specimens with smaller slenderness ratios. As to the specimens with smaller slenderness ratio, the way of core area loading helps the confinement effect of the outer FRP tube play well. As a result, the method of whole 
area loading is more suitable for the specimens with larger slenderness ratios, while that of core area loading is better for those with smaller slenderness ratios.

\section{Calculations of axial compressive bearing capability}

The newly put-forward composites of FRSLCs have similar axial compressive behavior with DSTCs. However, three parameters including the RCA replacement ratio of RAC which does not exist in DSTCs were designed for the FRSLC specimens in this test. To check whether the models for NAC composites are appropriate for these composites of FRSLCs, two theoretical models of ultimate bearing capacity based on the compression tests of DSTCs were chosen to make comparisons with the test results in this paper. One of the axial compressive bearing capability models for DSTLCs proposed by Qian and Liu (2006) [37] is based on the theoretical calculations for DSTSCs after introducing the reduction factor of the slenderness ratio. Without considering the contribution of the axial bearing capacity of the GFRP tube and within assuming that the fibre merely distributes along the hoop direction, this model for DSTLCs in Eq. 1 can be described as the axial compressive bearing capacity of the steel tube and concrete.

$$
N_{\mathrm{max}}=\phi_{l} N_{s, \mathrm{~m}}=\phi\left(f_{c} A t_{c} f\right)
$$

where $N_{\max }$ and $N_{s, \max }$ are the ultimate bearing capacity of DSTLCs and DSTSCs, respectively; $\phi_{l}$ is the reduction factor of the slenderness ratio of the specimen, which is given by Eq. $2 ; f_{c c}^{\prime}$ is the ultimate strength of confined concrete, which is given by Eq. $3 ; f_{y}$ is the yield strength of the steel tube; and $A_{c}$ and $A_{s}$ are the cross-section areas of concrete and the steel tube.

$$
\begin{gathered}
\phi_{l}=1-0.11 \sqrt{L / i-6} \\
f_{c c}^{\prime}=\lambda f_{c c(\text { solid })}^{\prime}
\end{gathered}
$$


where $L$ is the height of the column; $i$ is the gyration radius of the cross-section; $f_{c c(\text { solid })}$ is the ultimate strength of confined solid concrete; and $\lambda$ is the influencing factor related to the void ratio of the specimen and the diameter-to-thickness ratio of the steel tube. In this test, since the diameter-to-thickness ratios of the steel tubes are larger than 20, this influence can be ignored. The influencing factor $\lambda$ is considered to be decided by the void ratio only, which is given by Eq. 4 .

$$
\lambda=\lambda_{v}=1+0.062 K_{v}-0.74 K_{v}^{2}
$$

where $K_{v}$ is the void ratio, which is calculated via the inner diameter of the GFRP tube ( $\left.D_{0}\right)$ dividing by the outer diameter of the steel tube $\left(D_{s}\right)$; and $\lambda_{v}$ is the influencing factor of void ratio, and this influencing factor should not be less than 0.848 .

$f_{l} / f_{c}$ is the characteristic value of fibre for FRP confined concrete. As to the FRP material being cut from the prefabricated FRP tube with a filament winding angle, the lateral restraint strength of FRP $f_{l}$ is given by Eq. 5 . When this characteristic value $\left(f_{l} /\right.$ $f_{c}$ ) is less than 2.3, the ultimate strength of FRP confined solid concrete $f_{c c(s o l i d)}^{\prime}$ can be given by Eq. 6 .

$$
\begin{gathered}
f_{l}=3.5 f_{h, f r p} t_{f r p} / D_{0} \\
f_{c c(\text { solid })}^{\prime}=\left[1+2.911\left(f_{l} / f_{c}\right)-0.587\left(f_{l} / f_{c}\right)^{2}\right] f_{c}
\end{gathered}
$$

where $f_{h, f r p}, t_{f r p}$ and $D_{0}$ are the hoop tensile strength, the thickness and the outer diameter of the FRP tube, respectively; and $f_{c}$ is the compressive strength of unconfined concrete based on the concrete cylinders in this test.

Without considering the reduction factor $\phi_{l}$, the theoretical ultimate bearing capacity of FRSLCs $\left(N_{\operatorname{maxl}}\right)$ was calculated according to Eq. 1-6 listed in Table 6, and with considering the reduction factor, the ultimate bearing capacity of FRSLCs $\left(N_{\max 2}\right)$ was also calculated to compare with the test results.

From the ratios of theoretical values calculated by the second method to the test 
values in Table 6, the calculated values considering the influence of slenderness ratios, $N_{\max 2}$, generally underestimate the ultimate bearing capacity of FRSLCs by $35-45 \%$, especially for the specimens under the whole area loading. In other words, the reduction factor of the slenderness ratio for DSTLCs in Eq. 2 is not accurate for FRSLCs. It also reveals that the outer GFRP tube has exerted an influence on the axial stiffness and bearing capacity of the specimen to some extent. As a result, ignoring the axial effect of FRP tubes completely is inappropriate which leads to the predicted results too conservative. Also, the calculated values $\left(N_{\max 2}\right)$ are similar with different fluctuations of RCA replacement ratios and slenderness ratios, which indicates this calculated method is not sensitive to the influence of these two parameters. Compared to the values of $N_{\max 2}$, the calculated values without considering the influence of slenderness ratios $\left(N_{\max 1}\right)$ are more accurate on predicting the ultimate bearing capacity of FRSLCs with deviation ratios less than $15 \%$. The calculated values of $N_{\operatorname{maxl}}$ for the specimens under the whole area loading are approximately $10 \%$ less than their test values, which means the calculated models for DSTSCs are able to transform into predicting the ultimate bearing capacity of FRSLCs with slenderness ratios lower than 25.5 under the whole area loading. However, as to FRSLCs under the core area loading, the calculated values are higher, even as high as $45 \%$ more than the test results for Specimen Co-100-1200, which demonstrates that this model is not suitable for predicting their ultimate bearing capacity. Since the outer GFRP tubes have few contributions axially under the core area loading, it may result in the deficiency of specimens in stiffness. Thus, it is inappropriate to regard these specimens under the core area loading as short columns.

Another ultimate bearing capacity model for DSTLCs under eccentric compression was proposed by Lu (2013) [38] based on Yu's model (2010) [39], after amplifying 
the first-order bending moment according to the design specifications by the method of nominal curvature. As there is no eccentricity in this test, the calculations for DSTLCs and DSTSCs are given briefly in Eq. 7 and 8.

$$
\begin{aligned}
& N_{s, \max }=\alpha_{1} f_{c c} A_{c}\left[\theta-\frac{\sin (2 \pi \theta)}{2 \pi}-K_{v}^{2} \theta^{\prime}+K_{v}{ }^{2} \frac{\sin \left(2 \pi \theta^{\prime}\right)}{2 \pi}\right] \\
& +f_{y} A_{s}\left(\theta_{c}-\theta_{s}\right)+\frac{5}{6} \sigma_{f} A_{f} \theta_{f} \\
& N_{\max }=N_{s, \max } \frac{L^{2}}{\pi^{2}} \varsigma_{1} \varsigma_{2} \varphi_{b a l}=\frac{1}{3} \alpha_{1} f_{c c} A_{c} D_{0}\left[\frac{\sin ^{3}(\pi \theta)}{\pi}-K_{v}{ }^{3} \frac{\sin ^{3}\left(\pi \theta^{\prime}\right)}{\pi}\right] \\
& +\frac{1}{2} f_{y} A_{s} D_{s} \frac{\sin \left(\pi \theta_{c}\right)+\sin \left(\pi \theta_{s}\right)}{\pi}+\frac{5}{12} \frac{\sigma_{f} A_{f} D_{0}}{\pi} \sin \left(\pi \theta_{f}\right)
\end{aligned}
$$

where, $N_{\max }$ and $N_{s, \max }$ are the ultimate bearing capacity of DSTSCs under axial compression, respectively; $L$ is the height of the column; $K_{v}$ is the void ratio of the column; $D_{o}$ and $D_{s}$ are the inner diameter of the FRP tube and the outer diameter of the steel tube, respectively; $A_{f}, A_{c}$ and $A_{s}$ are the cross-section area of the FRP tube, concrete and steel tube, respectively; $2 \pi \theta$ and $2 \pi \theta^{\prime}$ are the central angles of the FRP tube and the steel tube corresponding to the height of the equivalent stress compressive zone of concrete; $\phi_{b a l}$ is the sectional curvature on critical failure; $f_{y}$ is the yield strength of the steel tube; $\sigma_{x, f}$ is the axial compressive strength of the FRP tube, which is calculated by $E_{x, f}$ multiplying $\varepsilon_{c u} ; f_{c c}$ and $\varepsilon_{c u}$ are the ultimate compressive strength and strain of the core concrete, and both can be given by the calculated models of confined concrete under axial compression [39].

All the parameters in Eq. 7 and 8, including the parameter of equivalent stress diagram of concrete $\left(\alpha_{1}\right)$, the configuration parameters related to the cross-section of the FRP tube $\left(\theta_{f}\right)$ the core concrete $\left(\theta_{c}\right)$ and the steel tube $\left(\theta_{s}\right)$, the influencing factor of sectional curvature $\left(\zeta_{1}\right)$ and the reduction factor related to the slenderness of specimens $\left(\zeta_{2}\right)$, can be obtained from the references [38].

When the ratio of $L$ to $D_{0}$ of the specimen is larger than the critical value $(L / D)_{c r}$ 
which is given by Eq. 9, its ultimate bearing capacity of the composite can be calculated according to Eq. 7 and 8, after assuming the value of $\theta$ from 0 and 1 .

$$
\left(\frac{L}{D}\right)_{c r}=\left(1-K_{v}\right)^{-0.16} \frac{4}{f_{c c} / f_{c}\left(1+0.05 \rho_{\varepsilon}\right)}
$$

where $\rho_{\varepsilon}$ is the strain ratio of the FRP tube; and $f_{c}$ is the compressive strength of unconfined concrete [39].

The ultimate bearing capacity of FRSLCs calculated via Lu's model $(2013)\left(N_{\max 3}\right)$ was listed in Table 7, together with the comparison of the calculated values and test results.

The ultimate bearing capacity of FRSLCs calculated via Lu's model (2013) basically coincides the test results of specimens under the whole area loading with deviations less than $10 \%$, and the deviations of specimens under the core area loading are around 10-20\% except Specimen Co-100-1200. As to the whole area loading, the prediction of the ultimate bearing capacity of FRSLCs calculated via Lu's model (2013) which takes the axial contribution of outer FRP tubes into consideration is more accurate than that calculated via Qian's model (2006). As to the core area loading, without burdening axial loads directly, the GFRP tube plays the role of constraining the core concrete along with the steel tube, thus Lu's model considering its axial contribution generally overestimates the ultimate bearing capacity of FRSLCs by $10-20 \%$. The Lu's model (2013) should be added an appropriate reduction factor around 0.8 related to the ratio of the stiffness of the outer FRP tube to that of the composite under the core area loading after more further experiments being done.

The comparisons between calculated values $N_{\max 1}$ and $N_{\max 3}$ to test results are shown in Fig. 17. The ratios of calculated values via Lu's model (2013) to test values are generally larger than those of calculated values via Qian's model to test ones. 
Compared with those via Qian's model, the calculated values via Lu's model (2013) are more accurate to predict the ultimate bearing capacity of FRSLCs under the whole area loading. However, as to the situation of core area loading, the calculated values of $N_{\max 3}$ are larger than test results by $10-20 \%$, and the calculated values of $N_{\max }$ are larger by $10 \%$.

\section{Conclusions}

The experimental results have shown that the axial performance of FRSLCs are similar with that of DSTLCs, indicating that RAC is applicable in the structural member of FRSCs. FRSCs have potential to alleviate the problem of demolished concrete and upgrade the applications of RAC, and this work helps provide an alternatively environmentally friendly structural composite in concrete structures. Compared to CFTs, these FRSCs with appropriate diameter-to-thickness ratios of the steel tubes have less weight, fewer costs, higher bearing capacity, better ductility, safer and easier construction, and more convenient usage in the service life. With the restraint of inner steel tubes and outer FRP tubes which have superior corrosion resistance, the negative impacts of RAC shrinkage and creeps decrease, and FRSCs are expected to have favorable long-term performance. FRSCs are particularly attractive for use as pier, piles, towers, or other load-bearing components of building structures in seismic regions or hostile environments. The following conclusions can be obtained from the axial compression test of FRSLCs.

(1) The ultimate bearing capacity of FRSLCs under the whole area loading has an increased tendency with an increase in RCA replacement ratios and slenderness ratios. The ultimate bearing capacity of FRSLCs under the core area loading has a decreased tendency with an increase in slenderness ratios. The ultimate bearing capacity of FRSLCs under the whole area loading is generally larger than that of FRSLCs under 
the core area loading.

(2) The lateral deflection at two sides of FRSLCs has an axisymmetric tendency based on the middle span, especially at the later stage of loading where the curve of the height - lateral deflection at different cross-sections of the specimen resembles half waves of a sinusoid. The distribution of strains around each cross-section obeys the plane cross-section assumption.

(3) The curves of load - mid-span strain in GFRP tubes can be divided into two segments. The parameter of RCA replacement ratios has little influence on the second stiffness of GFRP tubes. FRSLCs with smaller slenderness ratios have lager initial stiffness, but their strains increase less with an increase in loads. The bearing capacity and strains of GFRP tubes develop more adequately under the whole area loading. The curves of load - mid-span hoop strain in steel tubes can be divided into three segments. Three parameters have little influence on the initial stiffness of steel tubes. The steel tubes in FRSLCs have a short period of yielding and maintain completeness to constrain concrete.

(4) Qian's model (2006) considering the influence of slenderness ratios generally underestimates the ultimate bearing capacity of FRSLCs by $35-45 \%$, while this model without considering the influence of slenderness ratios generally underestimates the ultimate bearing capacity of FRSLCs under the whole area loading by $10-15 \%$. Lu's model (2013) is more accurate to predict the ultimate bearing capacity of FRSLCs under the whole area loading with a deviation less than $10 \%$, but this model generally overestimates that of FRSLCs under the core area loading by 10-20\%.

\section{Acknowledgments}

This work was supported by the National Natural Science Foundation of China (Project No.s 51278132 and 11472084) and Science and Technology Planning Project 
of Guangzhou City (Project No. 201704030057). The financial support is highly appreciated.

\section{References}

[1] Heshmati, M., Haghani, R., \& Al-Emrani, M. (2016). Effects of moisture on the long-term performance of adhesively bonded FRP/steel joints used in bridges. Composites Part B: Engineering, 92, 447-462.

[2] Sonnenschein, R., Gajdosova, K., \& Holly, I. (2016). FRP Composites and their Using in the Construction of Bridges. Procedia Engineering, 161, 477-482.

[3] Teng, J. G., Chen, J. F., \& Smith, S. T. (2002). FRP: Strengthened RC Structures. John Wiley and Sons Ltd, United Kingdom.

[4] Choi, E., Rhee, I., Park, J., et al. (2011). Seismic retrofit of plain concrete piers of railroad bridges using composite of FRP-steel plates. Composites Part B: Engineering, 42(5), 1097-1107.

[5] Wang, J., Liu, W., Zhou, D., et al. (2014). Mechanical behaviour of concrete filled double skin steel tubular stub columns confined by FRP under axial compression. Steel and Composite Structures, 17(4), 431-452.

[6] Teng, J. G., Lin, G., \& Yu, T. (2014). Analysis-oriented stress-strain model for concrete under combined FRP-steel confinement. Journal of Composites for Construction, 19(5), 04014084.

[7] Ozbakkaloglu, T., Fanggi, B. A. L., \& Zheng, J. (2016) Confinement model for concrete in circular and square FRP-concrete-steel double-skin composite columns. Materials \& Design, 96, 458-469.

[8] Teng, J. G., Yu, T., Wong, Y. L., et al. (2007). Hybrid FRP-concrete-steel tubular columns: concept and behavior. Construction and Building Materials, 21(4), 846-854. 
[9] Abdelkarim, O. I., \& ElGawady, M. A. (2016). Behavior of hollow FRP-concrete-steel columns under static cyclic axial compressive loading. Engineering Structures, 123, 77-88.

[10]Zhou, Y. W., Liu, X. M., Xing, F., et al. (2017). Behavior and modeling of FRP-concrete-steel double-skin tubular columns made of full lightweight aggregate concrete. Construction and Building Materials, 139, 52-63.

[11]Al-Salloum, Y. A., Almusallam, T. H., Elsanadedy, H. M., et al. (2016). Effect of elevated temperature environments on the residual axial capacity of RC columns strengthened with different techniques. Construction and Building Materials, 115, $345-361$.

[12]Vieira, D. R., Calmon, J. L., \& Coelho, F. Z. (2016). Life cycle assessment (LCA) applied to the manufacturing of common and ecological concrete: A review. Construction and Building Materials, 124, 656-666.

[13]Thomas, C., Setién, J., \& Polanco, J. A. (2016). Structural recycled aggregate concrete made with precast wastes. Construction and Building Materials, 114, 536-546.

[14]Shah, A., Jan, I. U., Khan, R. U., et al. (2013). Experimental investigation on the use of recycled aggregates in producing concrete. Structural Engineering and Mechanics, 47(4), 545-557.

[15]Khatib, J. M. (2005). Properties of concrete incorporating fine recycled aggregate. Cement and Concrete Research, 35(4), 763-769.

[16]Xiao, J. Z., Li, W. G., \& Poon, C. S. (2012). Recent studies on mechanical properties of recycled aggregate concrete in China-A review. Science China Technological Sciences, 55(6), 1463-1480.

[17]Ma, H., Xue, J., Zhang, X., et al. (2013). Seismic performance of steel-reinforced 
recycled concrete columns under low cyclic loads. Construction and Building Materials, 48, 229-237.

[18]Zeng, L., Li, L. J., Chen, G. M., et al. (2014). Experimental study on mechanical behavior of GFRP-recycled concrete-steel tubular columns under axial compression. China Civil Engineering Journal, 47(S2): 21-27. (in Chinese)

[19] Kashi, A., Rarnezanianpour, A. A., \& Moodi, F. (2017). Durability evaluation of retrofitted corroded reinforced concrete columns with FRP sheets in marine environmental conditions. Construction and Building Materials, 151, 520-533.

[20]Ma, C. K., Apandi, N. M., Yung, S. C. S., et al. (2017). Repair and rehabilitation of concrete structures using confinement: A review. Construction and Building Materials, 133, 502-515.

[21]Zyka, K. \& Mohajerani, A. (2016). Composite piles: A review. Construction and Building Materials, 107, 394-410.

[22]Hadi, M. N. S. \& Tung, M. T. (2014) Retrofitting nonseismically detailed exterior beam-column joints using concrete covers together with CFRP jacket. Construction and Building Materials, 63, 161-173.

[23]Zheng, J., \& Ozbakkaloglu, T. (2017). Sustainable FRP-recycled aggregate concrete-steel composite columns: behavior of circular and square columns under axial compression. Thin-Walled Structures, 120, 60-69.

[24]Xiao, J., Huang, Y., Yang, J., et al. (2012). Mechanical properties of confined recycled aggregate concrete under axial compression. Construction and Building Materials, 26(1), 591-603.

[25]Huang, H., Han, L. H., Tao, Z., et al. (2010). Analytical behaviour of concrete-filled double skin steel tubular (CFDST) stub columns. Journal of Constructional Steel Research, 66(4), 542-555. 
[26] Yu, T., Wong, Y. L., Teng, J. G., et al. (2006). Flexural behavior of hybrid FRP-concrete-steel double-skin tubular members. Journal of Composites for Construction, 10(5), 443-452.

[27]Mohamed, H. M., \& Masmoudi, R. (2010). Axial load capacity of concrete-filled FRP tube columns: Experimental versus theoretical predictions. Journal of Composites for construction, 14(2): 231-243.

[28]Feng, P., Cheng, S., Bai, Y., et al. (2015). Mechanical behavior of concrete-filled square steel tube with FRP-confined concrete core subjected to axial compression. Composite Structures, 123, 312-324.

[29]Karimi, K., Tait, M. J., \& El-Dakhakhni, W. W. (2013). Analytical modeling and axial load design of a novel FRP-encased steel-concrete composite column for various slenderness ratios. Engineering Structures, 46, 526-534.

[30]Vincent, T., \& Ozbakkloglu, T. (2015). Influence of FRP-to-concrete gap effect on axial strains of FRP-confined concrete columns. Advanced Materials Research, 1119.

[31]Liu, H., He, M., Guo, J., et al. (2015). Design-oriented modeling of circular FRP-wrapped concrete columns after sustained axial compression. Journal of Zhejiang University SCIENCE A, 16(1), 47-58.

[32]Lam, L., \& Teng, J. G. (2003). Design-oriented stress-strain model for FRP-confined concrete. Construction and Building Materials, 17(6), 271-489.

[33]Teng, J. G., Jiang, T., Lam, L., et al. (2009). Refinement of a design-oriented stress-strain model for FRP-confined concrete. Journal of Composite Construction, 13(4), 269-78.

[34]Jirawattanasomkul, T., Dawei, Z., \& Ueda, T. (2013). Prediction of the post-peak behavior of reinforced concrete columns with and without FRP-jacketing. 
Engineering Structures, 56, 1511-1526.

[35]Ghernouti, Y., \& Rabehi, B. (2011). FRP-confined short concrete columns under compressive loading: experimental and modeling investigation. Journal of Reinforced Plastics and Composites, 30(3), 241-255.

[36] Abdelkarim, O. I., \& ElGawady, M. A. (2014). Analytical and finite-element modeling of FRP-concrete-steel double-skin tubular columns. Journal of Bridge Engineering, 20(8), B4014005.

[37]Qian, J.R., \& Liu, X. M. (2006). Experiment of FRP-concrete-steel double-skin tubular long columns under axial compressive load. Concrete, 9, 31-34. (in Chinese)

[38]Lu, Z. G. (2012). Design Method of FRP-Concrete-Steel Double-Skin Tubular Columns. Dissertation, Zhejiang University. (in Chinese)

[39] Yu, T., Teng, J. G., \& Wong, Y. L. (2010). Stress-Strain Behavior of Concrete in Hybrid FRP-Concrete-Steel Double-Skin Tubular Columns. Journal of Structural Engineering, 136(4), 379-389.

[40]ASTM A501/A501M-14, (2014). Standard Specification for Hot-Formed Welded and Seamless Carbon Steel Structural Tubing [S], ASTM International, West Conshohocken, PA.

[41]ISO 6892-1: 2016, (2016). Metallic materials - Tensile testing - Part 1: Method of test at room temperature $[\mathrm{S}]$.

[42]ASTM D2290-16, (2016). Standard Test Method for Apparent Hoop Tensile Strength of Plastic or Reinforced Plastic Pipe [S], ASTM International, West Conshohocken, PA.

[43]ASTM C39/C39M-18, (2018). Standard Test Method for Compressive Strength of Cylindrical Concrete Specimens [S], ASTM International, West Conshohocken, 
PA.

[44]ASTM C469/C469M-14, (2014). Standard Test Method for Static Modulus of Elasticity and Poisson's Ratio of Concrete in Compression [S], ASTM International, West Conshohocken, PA.

[45]ISO 679: 2009, (2009). Cement - Test methods - Determination of strength [S].

[46]McGinnis, M. J., Davis, M., Rosa, A., et al. (2017). Strength and stiffness of concrete with recycled concrete aggregates. Construction and Building Materials, $154,258-269$.

[47]Dong, J. F., Wang, Q. Y., \& Guan, Z. W. (2016) Material and structural response of steel tube confined recycled earthquake waste concrete subjected to axial compression. Magazine of Concrete Research, 68(6), 271-282.

\section{Table and Figure captions}

Table 1 Design of FRSLC specimens

Table 2 Main properties of steel tubes

Table 3 Main properties of GFRP tubes

Table 4 Designed mixture proportions and properties of concrete

Table 5 Bearing capacity and mid-span deflection of FRSLC specimens

Table 6 Calculated ultimate bearing capacity of FRSLCs using Qian's model (2006)

Table 7 calculated ultimate bearing capacity of FRSLCs using Lu's model (2013)

Fig. 1 Dimensional sketches of specimens (Unit: mm): a) top view; b) side view

Fig. 2 Tensile test of steel coupons: a) loading; b) steel coupons

Fig. 3 Stress-strain curve of steel coupons

Fig. 4 Split-disk test of GFRP rings 
Fig. 5 Preparation of specimens

Fig. 6 Test set-up and instruments

Fig. 7 Arrangements of strain gauges and LVDTs: a) side view; b) top view

Fig. 8 Failure modes: a)-1)

Fig. 9 Influence of RCA replacement ratios on ultimate bearing capacity of specimens

Fig.10 Influence of slenderness ratios on ultimate bearing capacity of specimens: a) whole area loading; b) core area loading

Fig.11 Influence of loading methods on ultimate bearing capacity of specimens: a) same slenderness ratio; b) same RCA replacement ratio

Fig. 12 Curves of load - mid-span deflection of specimens: a)-f)

Fig.13 Lateral deflection curves at three cross-sections under different loads: a) Cw-0-1200; b) Cw-30-1200; c) Cw-50-1200; d) Cw-100-900; e) Cw-100-1500; f) Co-0-1200

Fig. 14 Axial strains in GFRP tubes at cross-sections under different loads: a) Cw-100-1200 at Section B; b) Co-100-1200 at Section B; c) Cw-100-1200 at Section C; d) Co-100-1200 at Section C; e) Cw-100-1500 at Section C; f) Co-100-1500 at Section C

Fig. 15 Curves of load - mid-span strain in GFRP tubes: a)-f)

Fig. 16 Curves of load - mid-span strain in steel tubes: a)-f)

Fig.17 Contrast between test and calculated results of FRSLC specimens: a) whole area loading; b) core area loading

Table 1 Design of FRSLC specimens

\begin{tabular}{|c|c|c|c|c|}
\hline Specimen ${ }^{*}$ & Loading method & $\begin{array}{c}\text { RCA replacement } \\
\text { ratio } R(\%)\end{array}$ & $\begin{array}{l}\text { Height } L \\
(\mathrm{~mm})\end{array}$ & $\begin{array}{c}\text { Slenderness } \\
\text { ratio } L / i\end{array}$ \\
\hline
\end{tabular}




\begin{tabular}{ccccc}
\hline Cw-0-1200 & whole area & 0 & 1200 & 20.4 \\
Cw-30-1200 & whole area & 30 & 1200 & 20.4 \\
Cw-50-1200 & whole area & 50 & 1200 & 20.4 \\
Cw-70-1200 & whole area & 70 & 1200 & 20.4 \\
Cw-100-1200 & whole area & 100 & 1200 & 20.4 \\
Cw-100-900 & whole area & 100 & 900 & 15.3 \\
Cw-100-1500 & whole area & 100 & 1500 & 25.5 \\
Co-0-1200 & core area & 0 & 1200 & 20.4 \\
Co-50-1200 & core area & 50 & 1200 & 20.4 \\
Co-100-1200 & core area & 100 & 1200 & 20.4 \\
Co-100-900 & core area & 100 & 900 & 15.3 \\
\hline
\end{tabular}

${ }^{*}$ Notes: $\mathrm{Cm}-R-L$ refers to an FRSLC with an RCA replacement ratio of $R$ and a column height of $L$; $m$ refers to the loading method. The slenderness ratio is the ratio of the column height $L$ to the gyration radius of the cross-section $i$.

Table 2 Main properties of steel tubes

\begin{tabular}{ccccc}
\hline $\begin{array}{c}\text { Outer diameter } \\
D_{s}(\mathrm{~mm})\end{array}$ & $\begin{array}{c}\text { Thickness } \\
t_{s}(\mathrm{~mm})\end{array}$ & $\begin{array}{c}\text { Yield strength } f_{y} \\
(\mathrm{MPa})\end{array}$ & $\begin{array}{c}\text { Ultimate strength } f_{u} \\
(\mathrm{MPa})\end{array}$ & $\begin{array}{c}\text { Elastic modulus } E_{s} \\
(\mathrm{GPa})\end{array}$ \\
\hline 121 & 5 & 365.25 & 543.75 & 179.6 \\
\hline
\end{tabular}

Table 3 Main properties of GFRP tubes 


\begin{tabular}{cccccccc}
\hline Inner & Thickness & Hoop & Hoop & Hoop & Axial & Axial & Axial \\
diameter & $t_{f r p}$ & tensile & elastic & Poisson & elastic & compressive & Poisson \\
$D_{0}(\mathrm{~mm})$ & $(\mathrm{mm})$ & strength & modulus & ratio & modulus & strength & ratio \\
& & $f_{h, f r p}$ & $E_{h, f}$ & $v_{h, f}$ & $E_{x, f}$ & $\sigma_{x, f}$ & $v_{x, f}$ \\
& $(\mathrm{MPa})$ & $(\mathrm{GPa})$ & & $(\mathrm{GPa})$ & $(\mathrm{MPa})$ & \\
\hline 2 & 652 & 42 & 0.26 & 12.9 & 278 & 0.11 \\
\hline
\end{tabular}

Table 4 Designed mixture proportions and properties of concrete

\begin{tabular}{cccccccccc}
\hline Concrete & $\begin{array}{c}\text { Cement } \\
\left(\mathrm{kg} / \mathrm{m}^{3}\right)\end{array}$ & $\begin{array}{c}\text { Water } \\
\left(\mathrm{kg} / \mathrm{m}^{3}\right)\end{array}$ & $\begin{array}{c}\text { Sand } \\
\left(\mathrm{kg} / \mathrm{m}^{3}\right)\end{array}$ & $\begin{array}{c}\text { Natural } \\
\text { coarse } \\
\text { aggregate } \\
\left(\mathrm{kg} / \mathrm{m}^{3}\right)\end{array}$ & $\begin{array}{c}\text { Recycled } \\
\text { coarse } \\
\text { aggregate } \\
\left(\mathrm{kg} / \mathrm{m}^{3}\right)\end{array}$ & $\begin{array}{c}\text { Slump } \\
(\mathrm{mm})\end{array}$ & $\begin{array}{c}\text { Compressive } \\
\text { strength of } \\
\text { cubes } f_{c u} \\
(\mathrm{MPa})\end{array}$ & $\begin{array}{c}\text { Compressive } \\
\text { strength of } \\
\text { cylinders } f_{c} \\
(\mathrm{MPa})\end{array}$ & $\begin{array}{c}\text { Elastic } \\
\text { modulus }\end{array}$ \\
$E_{c}$ \\
$\mathrm{NC}$ & 479.6 & 235 & 735.9 & 899.5 & 0 & 160 & 51.84 & 47.17 & 2.97 \\
RC-30 & 479.6 & 235 & 735.9 & 629.6 & 237.1 & 135 & 58.45 & 49.15 & 2.82 \\
RC-50 & 479.6 & 235 & 735.9 & 449.7 & 395.2 & 95 & 44.96 & 43.95 & 2.54 \\
RC-70 & 479.6 & 235 & 735.9 & 269.8 & 553.3 & 70 & 54.65 & 45.41 & 2.76 \\
RC-100 & 479.6 & 235 & 735.9 & 0 & 790.4 & 45 & 59.74 & 47.75 & 2.81 \\
\hline
\end{tabular}

Notes: RC- $R$ refers to recycled aggregate concrete with an RCA replacement ratio of $R$. NC indicates natural aggregate concrete.

Table 5 Bearing capacity and mid-span deflection of FRSLC specimens

\begin{tabular}{cccccc}
\hline Specimen & $P_{k}(\mathrm{kN})$ & $P_{c o}(\mathrm{kN})$ & $\delta_{k}(\mathrm{~mm})$ & $\delta_{\max }(\mathrm{mm})$ & $\delta_{\text {max }} / \delta_{k}$ \\
\hline Cw-0-1200 & 3128.40 & 939.48 & 4.46 & 4.52 & 1.01 \\
CW-30-1200 & 3637.95 & 978.92 & 5.30 & 5.48 & 1.03 \\
Cw-50-1200 & 3709.05 & 875.35 & 8.78 & 10.88 & 1.24
\end{tabular}




\begin{tabular}{cccccc} 
Cw-70-1200 & 3428.65 & 904.43 & 6.30 & 9.10 & 1.44 \\
Cw-100-1200 & 3685.35 & 951.03 & 7.02 & 7.20 & 1.03 \\
Cw-100-900 & 3203.45 & 951.03 & 0.92 & 0.98 & 1.07 \\
Cw-100-1500 & 3258.75 & 951.03 & 23.42 & 24.28 & 1.04 \\
Co-0-1200 & 2634.65 & 939.48 & 4.66 & 5.66 & 1.21 \\
Co-50-1200 & 3393.05 & 875.35 & 3.44 & 3.58 & 1.04 \\
Co-100-1200 & 2176.45 & 951.03 & 8.14 & 8.38 & 1.03 \\
Co-100-900 & 2974.35 & 951.03 & 0.60 & 0.74 & 1.23 \\
Co-100-1500 & 2907.20 & 951.03 & 12.86 & 13.36 & 1.04 \\
\hline
\end{tabular}

Table 6 Calculated ultimate bearing capacity of FRSLCs using Qian's model (2006)

\begin{tabular}{|c|c|c|c|c|c|c|c|c|}
\hline Specimen & $\lambda$ & $\begin{array}{c}f_{c} \\
(\mathrm{MPa})\end{array}$ & $f_{l} / f_{c}$ & $\begin{array}{c}P_{k} \\
(\mathrm{kN})\end{array}$ & $\begin{array}{l}N_{\max l} \\
(\mathrm{kN})\end{array}$ & $\begin{array}{r}N_{\max 2} \\
(\mathrm{kN})\end{array}$ & $N_{\max 1} / P_{k}$ & $N_{\max 2} / P_{k}$ \\
\hline $\mathrm{Cw}-0-1200$ & 20.4 & 47.17 & 0.98 & 3128.40 & 2975.83 & 1822 & 0.95 & 0.58 \\
\hline $\mathrm{Cw}-30-1200$ & 20.4 & 49.15 & 0.93 & 3637.95 & 3321.86 & 1993.12 & 0.91 & 0.55 \\
\hline $\mathrm{Cw}-50-1200$ & 20.4 & 43.95 & 1.04 & 3709.05 & 3293.80 & 1976.28 & 0.89 & 0.53 \\
\hline $\mathrm{Cw}-70-1200$ & 20.4 & 45.41 & 1.01 & 3428.65 & 3228.49 & 1937.09 & 0.94 & 0.56 \\
\hline $\mathrm{Cw}-100-1200$ & 20.4 & 47.75 & 0.96 & 3685.35 & 3159.34 & 1973.58 & 0.86 & 0.54 \\
\hline Cw-100-900 & 15.3 & 47.75 & 0.96 & 3203.45 & 3159.34 & 1973.58 & 0.98 & 0.62 \\
\hline Cw-100-1500 & 25.5 & 47.75 & 0.96 & 3258.75 & 3159.34 & 1973.58 & 0.96 & 0.61 \\
\hline Co- $0-1200$ & 20.4 & 47.17 & 0.98 & 2634.65 & 2975.83 & 1822.00 & 1.13 & 0.69 \\
\hline Co-50-1200 & 20.4 & 43.95 & 1.04 & 3393.05 & 3183.80 & 1976.28 & 0.94 & 0.66 \\
\hline
\end{tabular}




\begin{tabular}{lccccccccc}
\hline Co-100-1200 & 20.4 & 47.75 & 0.96 & 2176.45 & 3159.34 & 1973.58 & 1.45 & 0.90 \\
Co-100-900 & 15.3 & 47.75 & 0.96 & 2974.35 & 3159.34 & 1973.58 & 1.06 & 0.66 \\
Co-100-1500 & 25.5 & 47.75 & 0.96 & 2907.20 & 3159.34 & 1973.58 & 1.08 & 0.68 \\
\hline
\end{tabular}

Table 7 calculated ultimate bearing capacity of FRSLCs using Lu's model (2013)

\begin{tabular}{|c|c|c|c|c|c|c|c|c|c|}
\hline Specimen & $\rho_{\varepsilon}$ & $f_{c d} / f_{c}$ & $L / D_{o}$ & $(L / D)_{c r}$ & $\zeta_{2}$ & $\phi_{b a l}$ & $\theta$ & $\begin{array}{l}N_{\max 3} \\
(\mathrm{kN})\end{array}$ & $N_{\max 3} / P_{k}$ \\
\hline Cw-0-1200 & 1.574 & 1.88 & 6 & 2.29 & 1 & 0.00020 & 0.67792 & 3131.00 & 1.00 \\
\hline $\mathrm{Cw}-30-1200$ & 1.805 & 1.82 & 6 & 2.34 & 1 & 0.00018 & 0.69243 & 3527.88 & 0.97 \\
\hline $\mathrm{Cw}-50-1200$ & 2.960 & 1.89 & 6 & 2.14 & 1 & 0.00017 & 0.70429 & 3757.14 & 1.01 \\
\hline Cw-70-1200 & 2.387 & 1.88 & 6 & 2.20 & 1 & 0.00018 & 0.69564 & 3496.13 & 1.02 \\
\hline Cw-100-1200 & 3.083 & 1.80 & 6 & 2.23 & 1 & 0.00016 & 0.69974 & 3648.29 & 0.99 \\
\hline $\mathrm{Cw}-100-900$ & 3.083 & 1.80 & 4.5 & 2.23 & 1 & 0.00016 & 0.68765 & 3517.88 & 1.09 \\
\hline Cw-100-1500 & 3.083 & 1.80 & 7.5 & 2.23 & 0.97 & 0.00016 & 0.67683 & 3257.48 & 0.99 \\
\hline Co- $0-1200$ & 1.574 & 1.88 & 6 & 2.29 & 1 & 0.00020 & 0.67792 & 3151.00 & 1.20 \\
\hline Co-50-1200 & 2.960 & 1.89 & 6 & 2.14 & 1 & 0.00017 & 0.70429 & 3757.14 & 1.11 \\
\hline Co-100-1200 & 3.083 & 1.80 & 6 & 2.23 & 1 & 0.00016 & 0.69974 & 3648.29 & 1.67 \\
\hline Co-100-900 & 3.083 & 1.80 & 4.5 & 2.23 & 1 & 0.00016 & 0.68765 & 3517.88 & 1.18 \\
\hline Co-100-1500 & 3.083 & 1.80 & 7.5 & 2.23 & 0.97 & 0.00016 & 0.67683 & 3257.48 & 1.12 \\
\hline
\end{tabular}




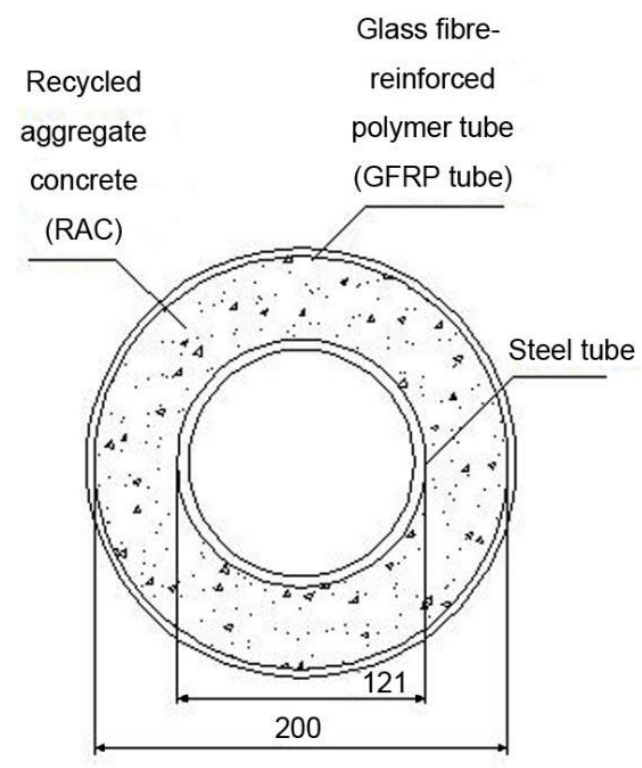

(a) top view

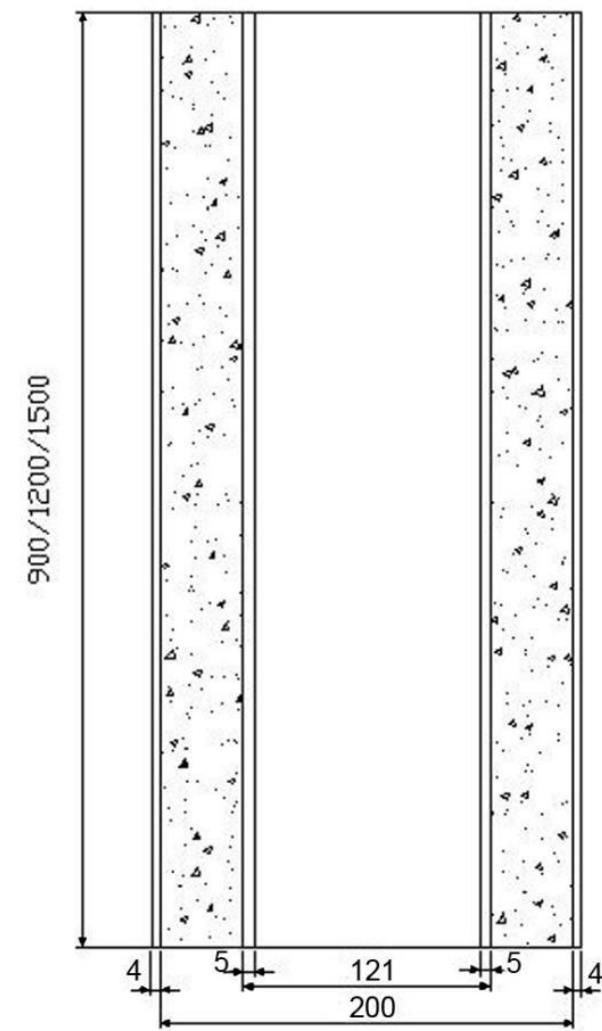

(b) side view

Fig. 1 Dimensional sketches of specimens (Unit: mm)

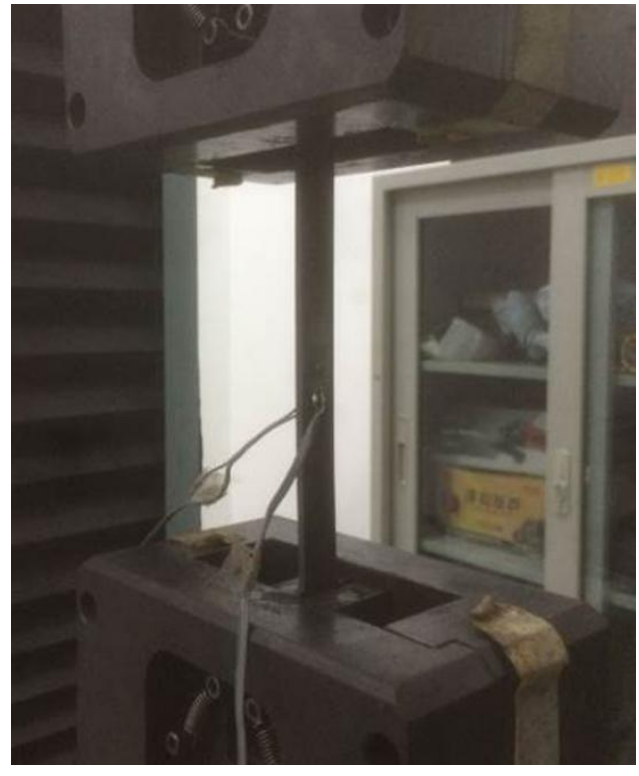

(a) loading

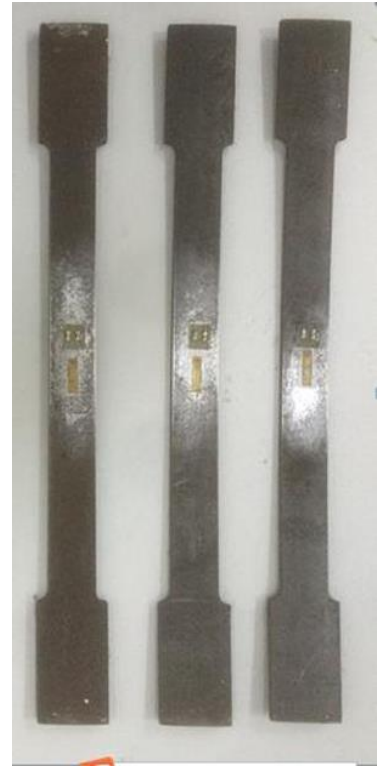

(b) steel coupons

Fig. 2 Tensile test of steel coupons 


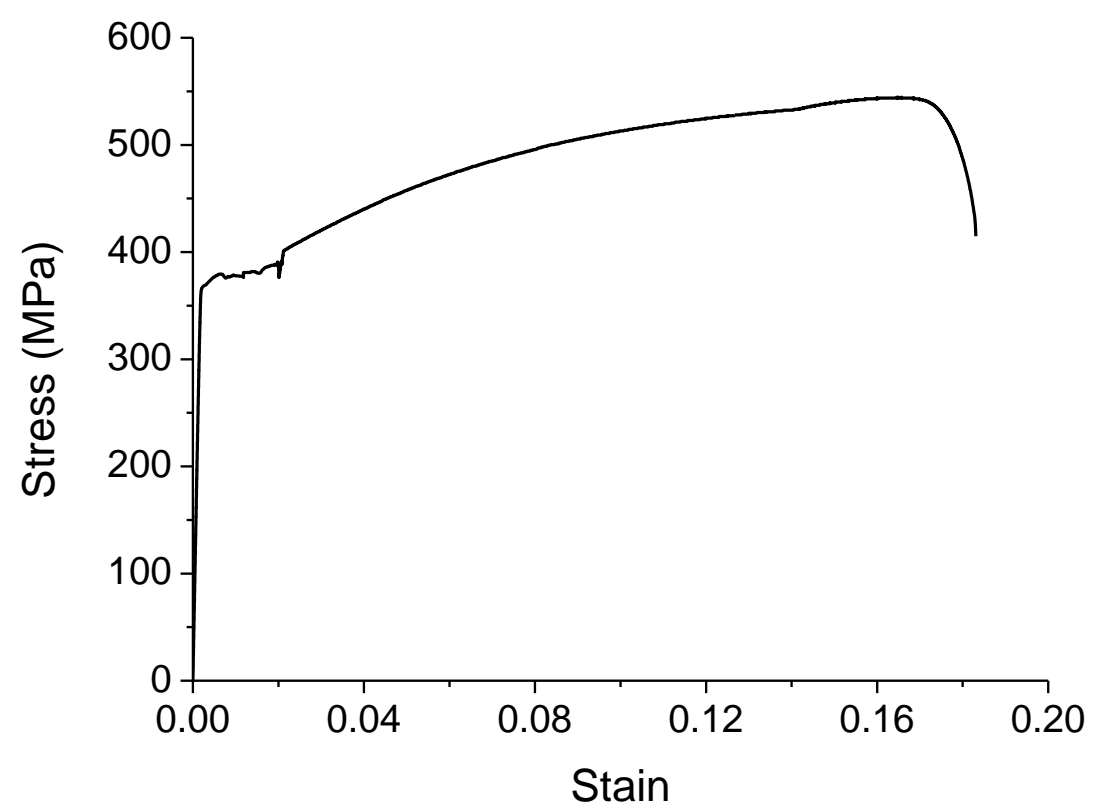

Fig. 3 Stress-strain curve of steel coupons

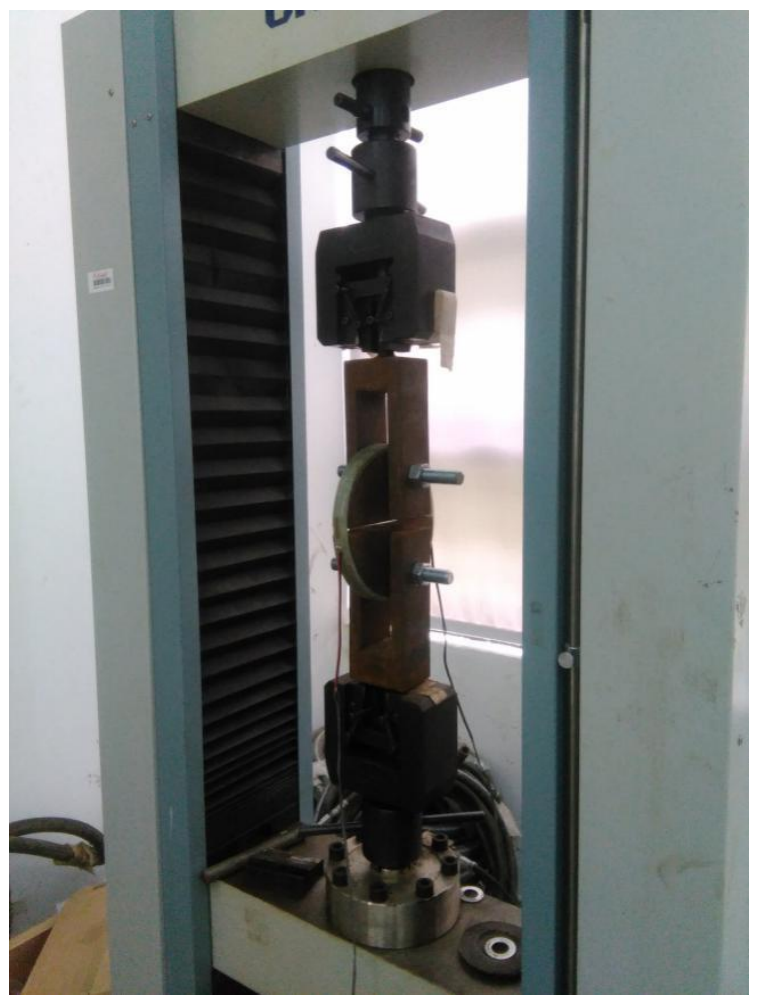

Fig. 4 Split-disk test of GFRP rings 


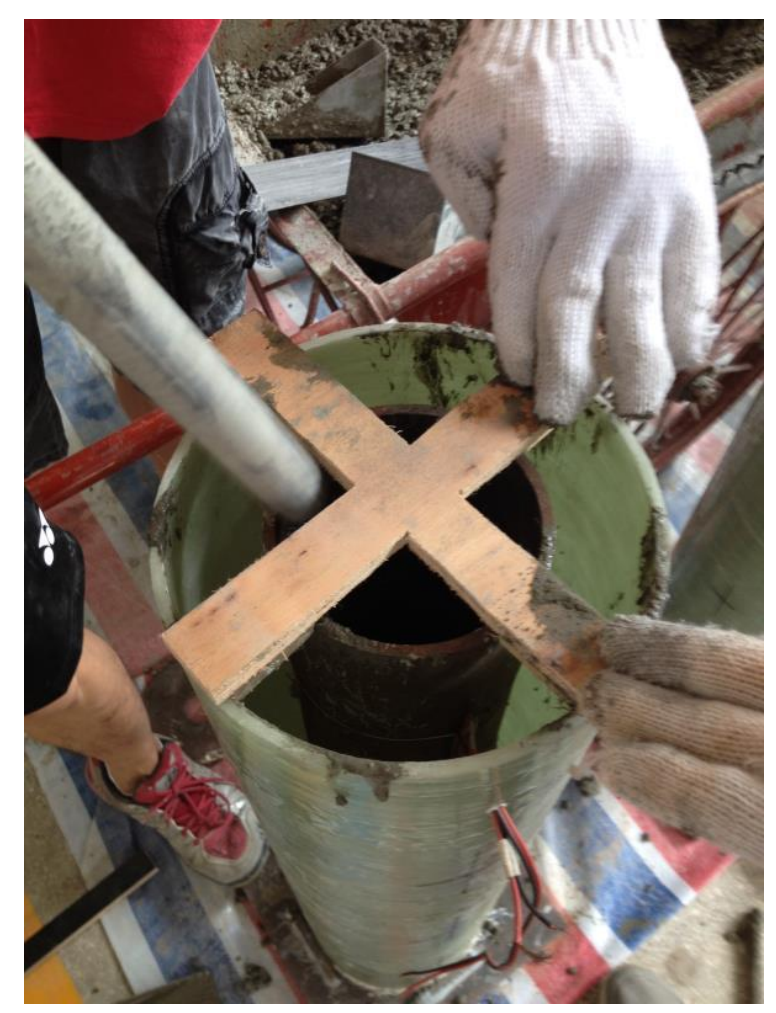

Fig. 5 Preparation of specimens

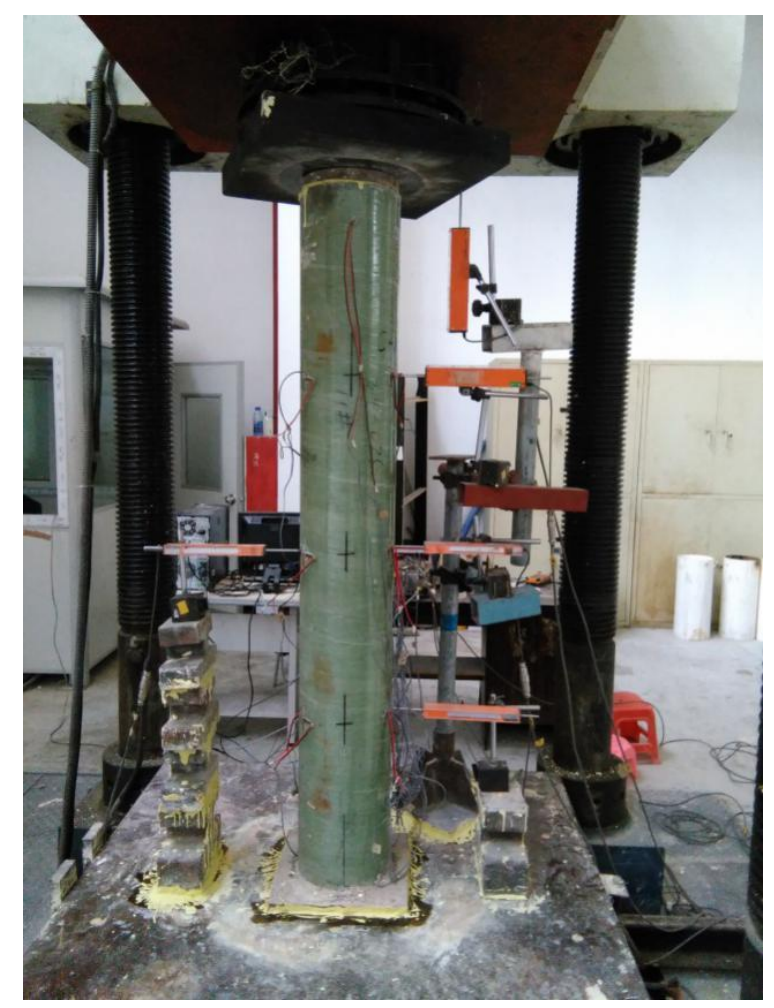

Fig. 6 Test set-up and instruments 


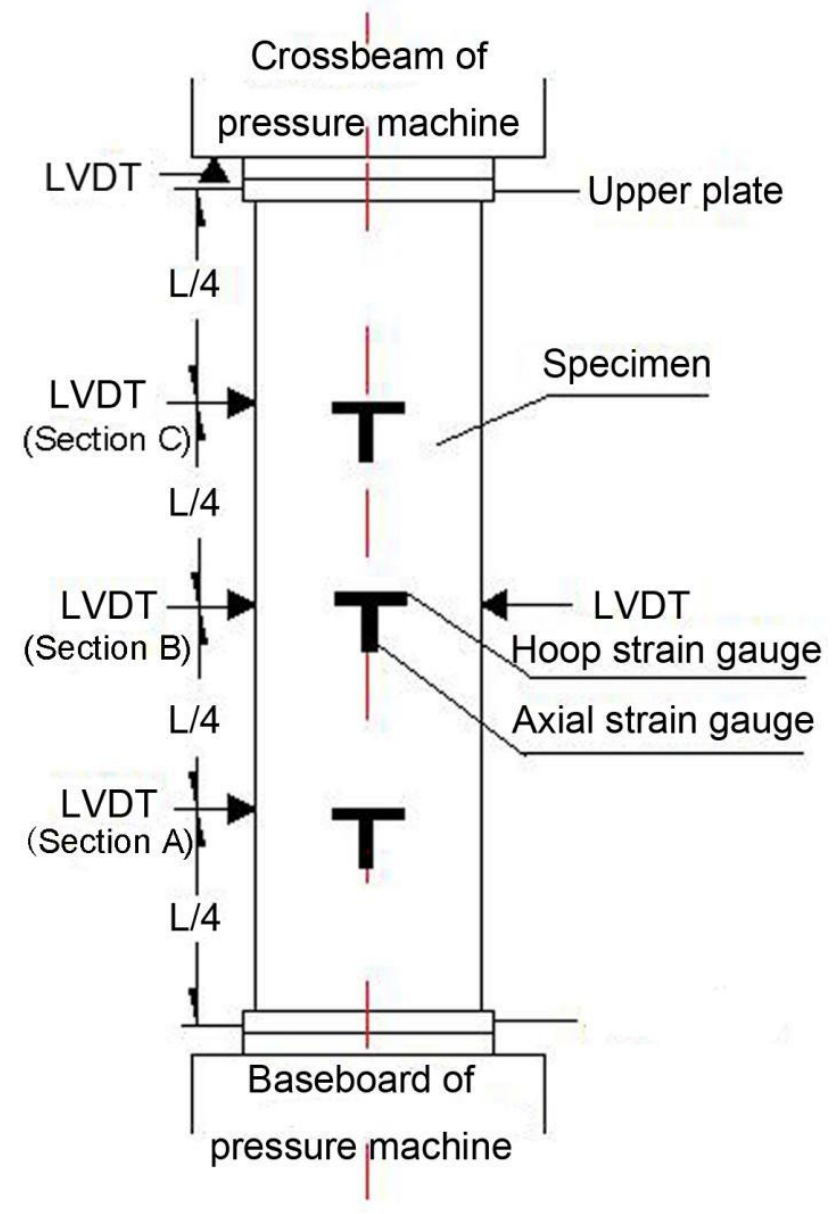

(a) side view

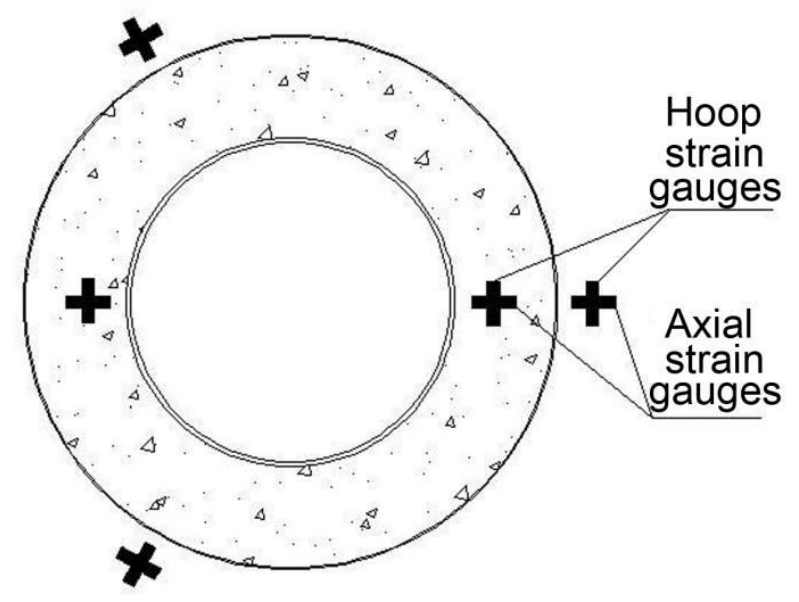

(b) top view

Fig. 7 Arrangements of strain gauges and LVDTs 


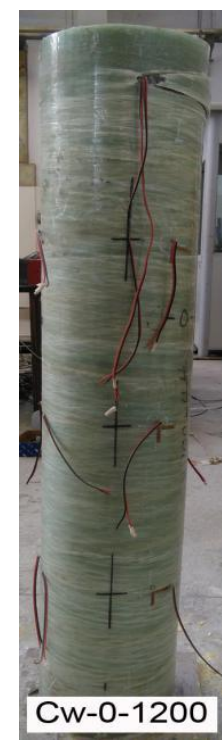

(a)

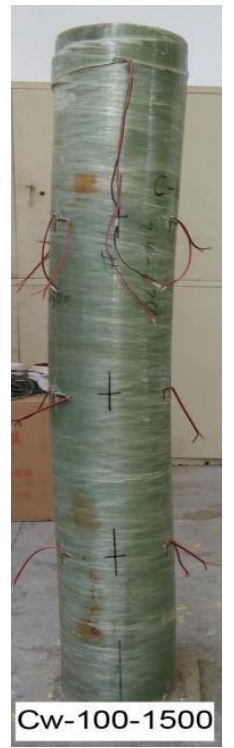

(g)

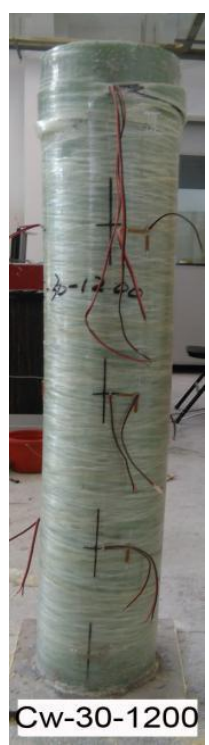

(b)

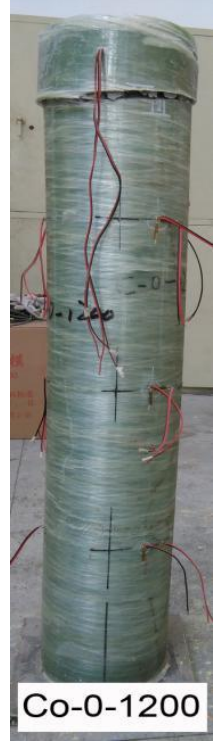

(h)

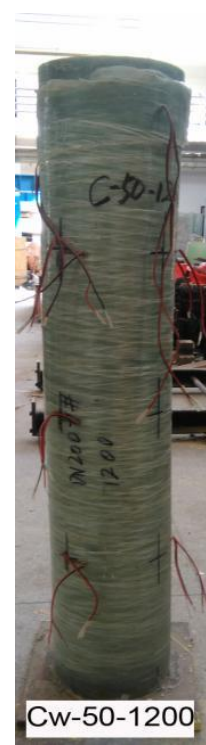

(c)

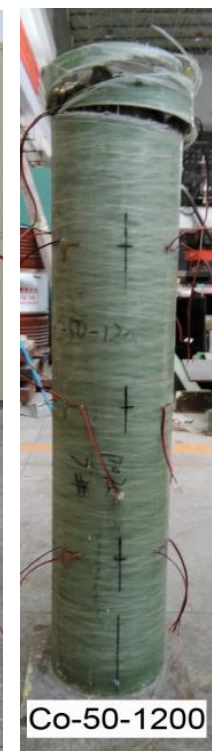

(i)

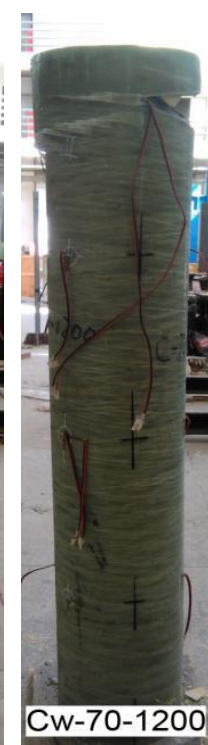

(d)

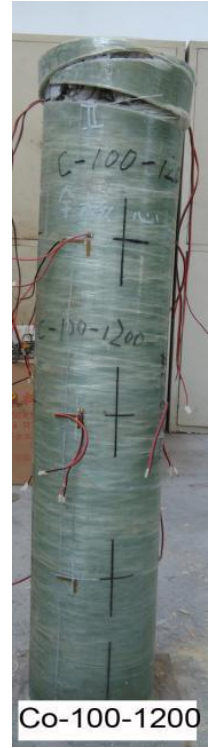

(j)

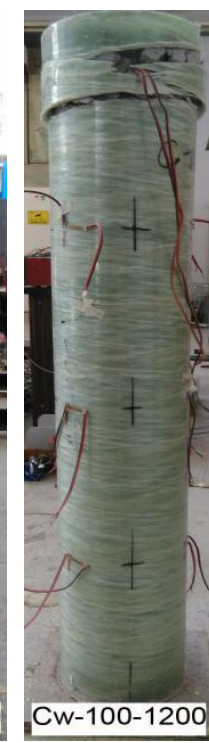

(e)

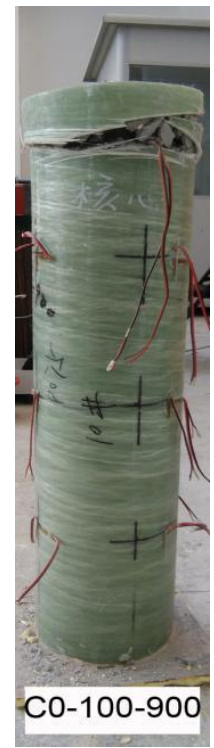

(k)

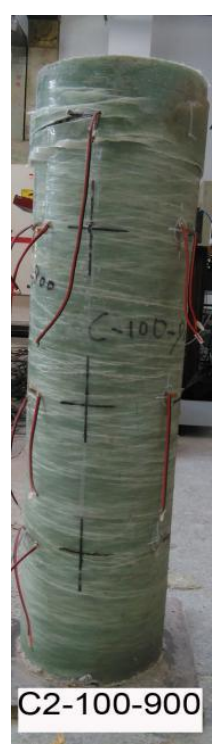

(f)

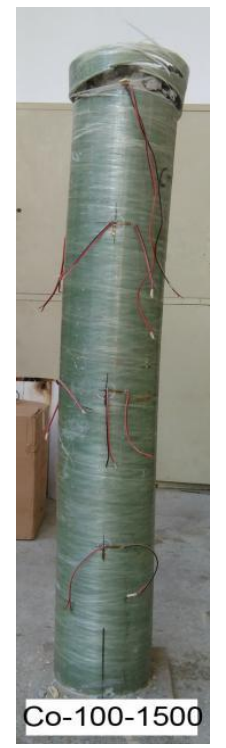

(1)

Fig. 8 Failure modes 


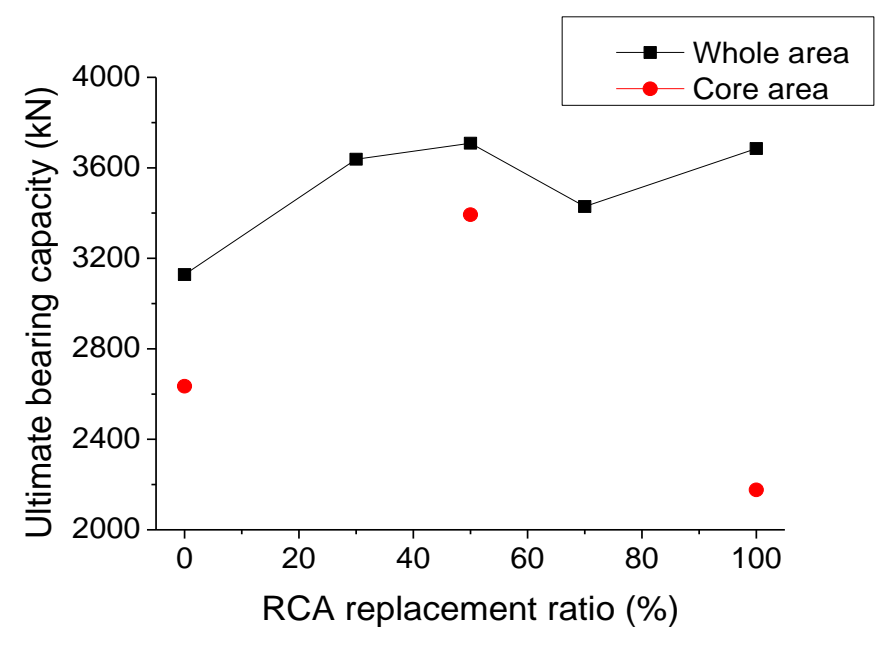

Fig. 9 Influence of RCA replacement ratios on ultimate bearing capacity of specimens

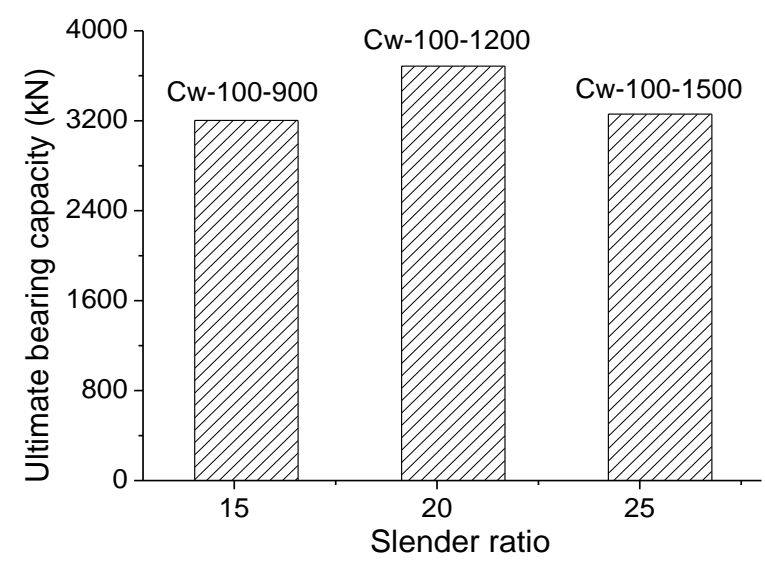

(a) whole area loading

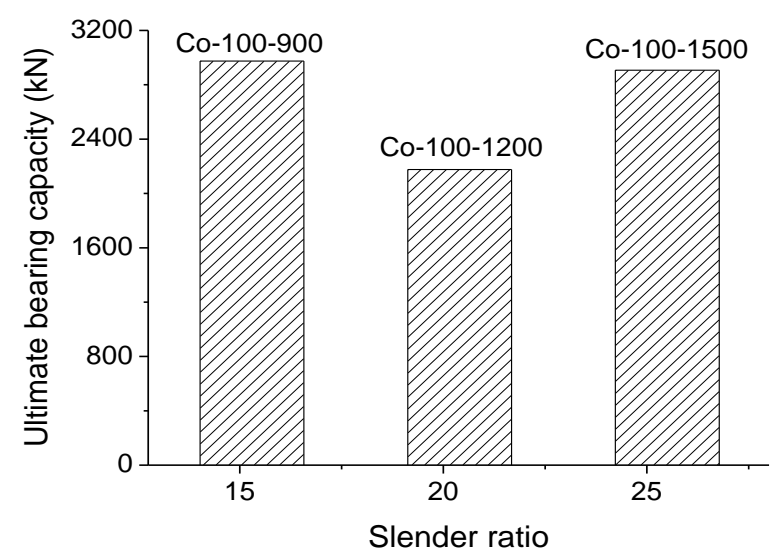

(b) core area loading

Fig.10 Influence of slenderness ratios on ultimate bearing capacity of specimens 


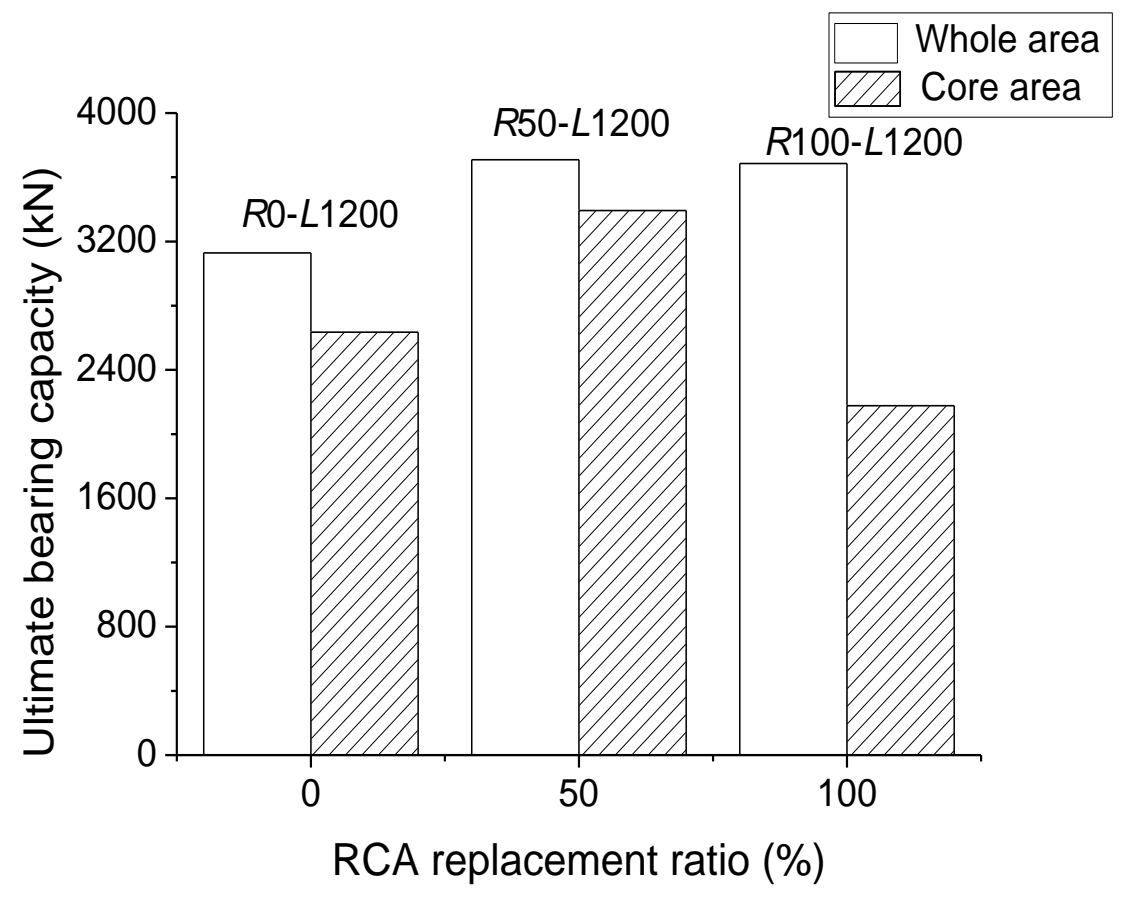

(a) same slenderness ratio

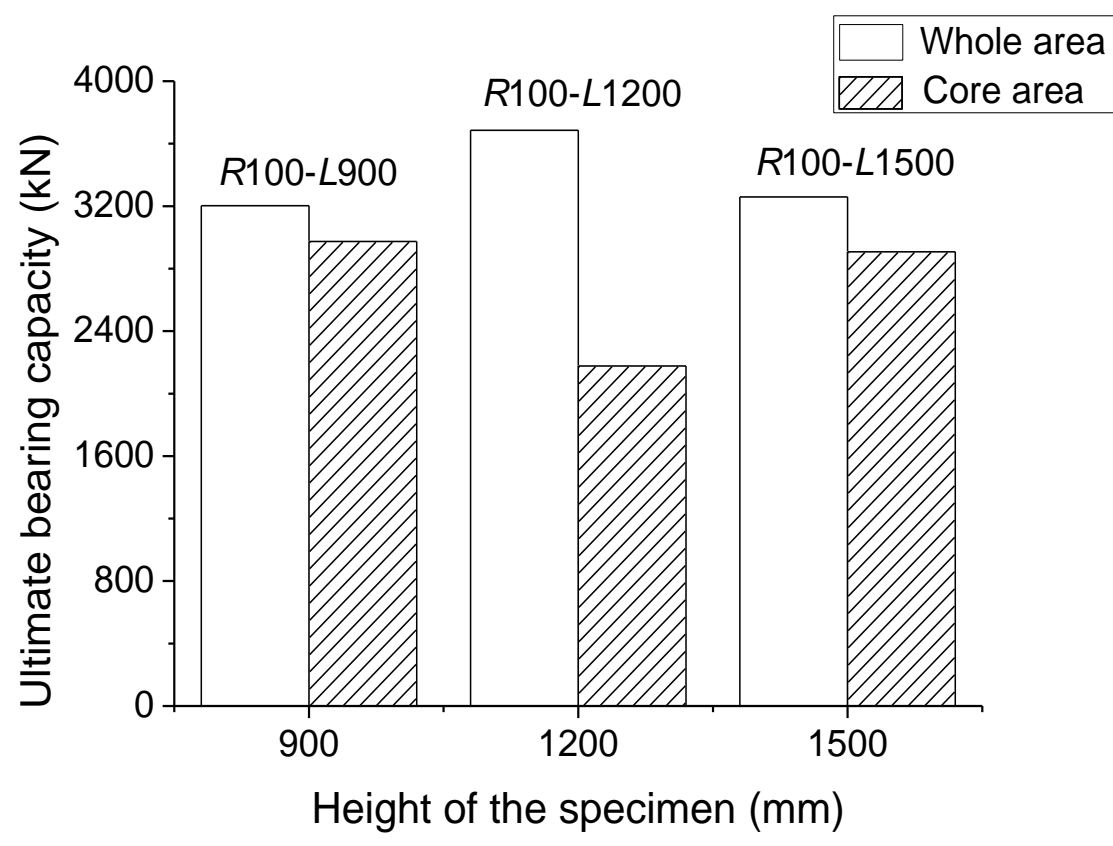

(b) same RCA replacement ratio

Fig.11 Influence of loading methods on ultimate bearing capacity of specimens 


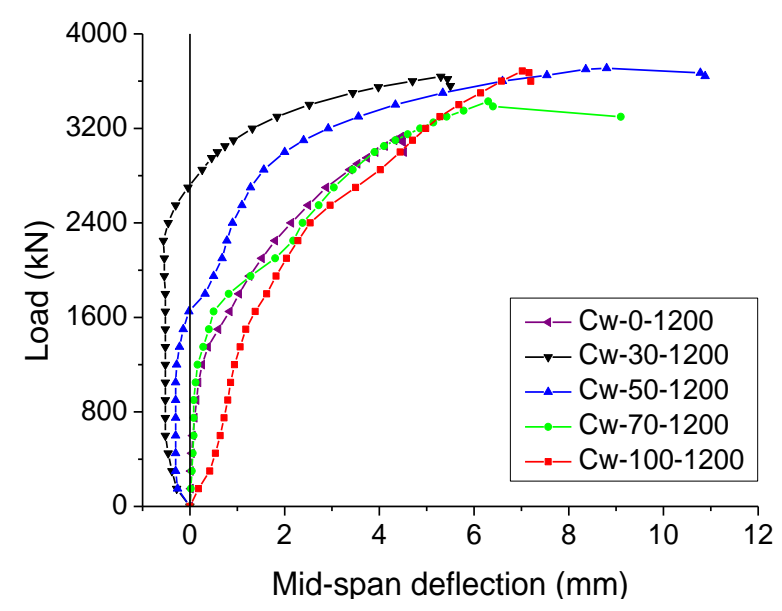

(a)

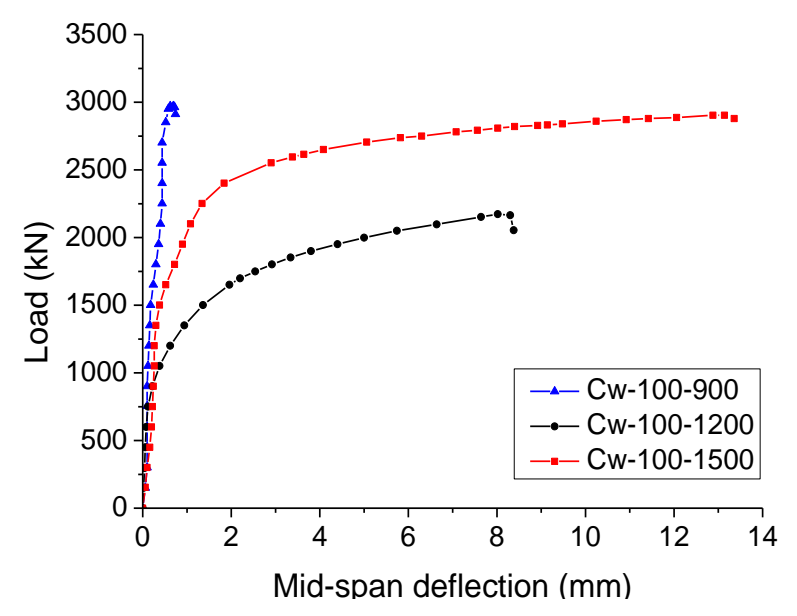

(c)

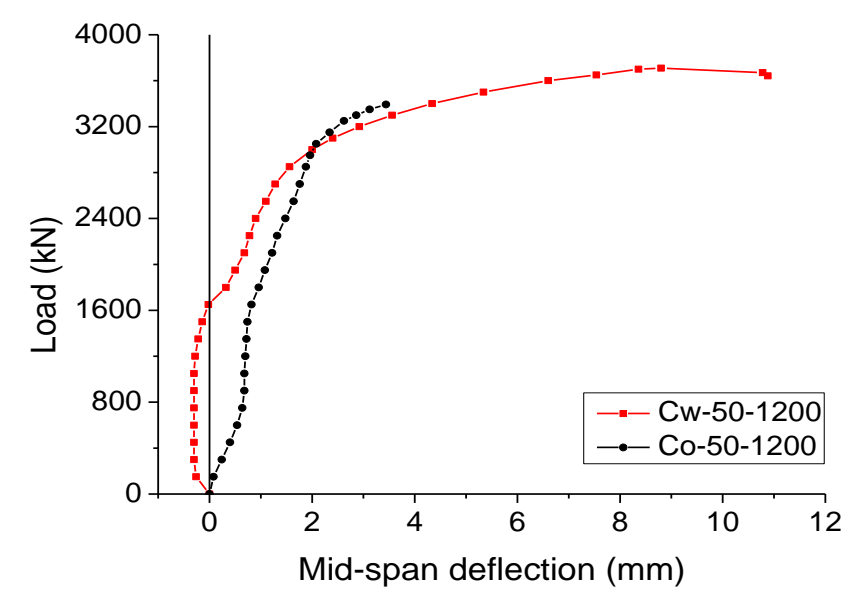

(e)

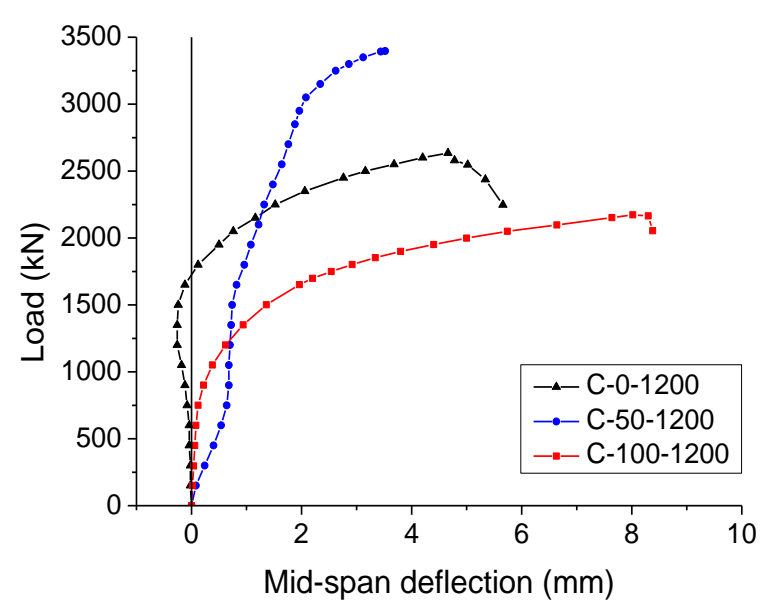

(b)

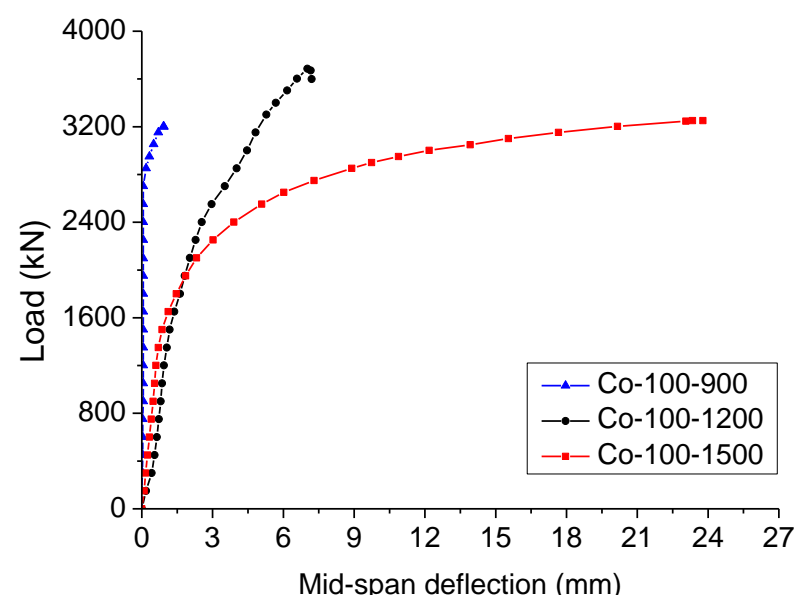

(d)

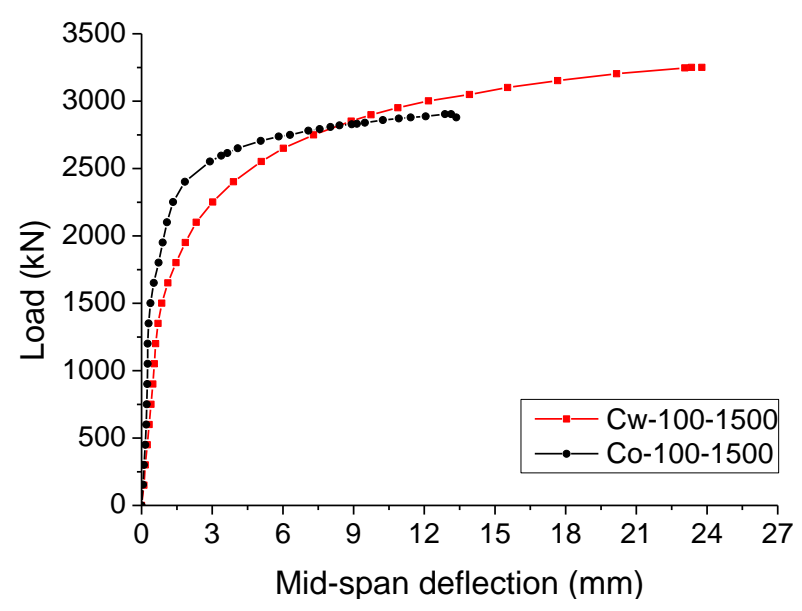

(f)

Fig. 12 Curves of load - mid-span deflection of specimens 


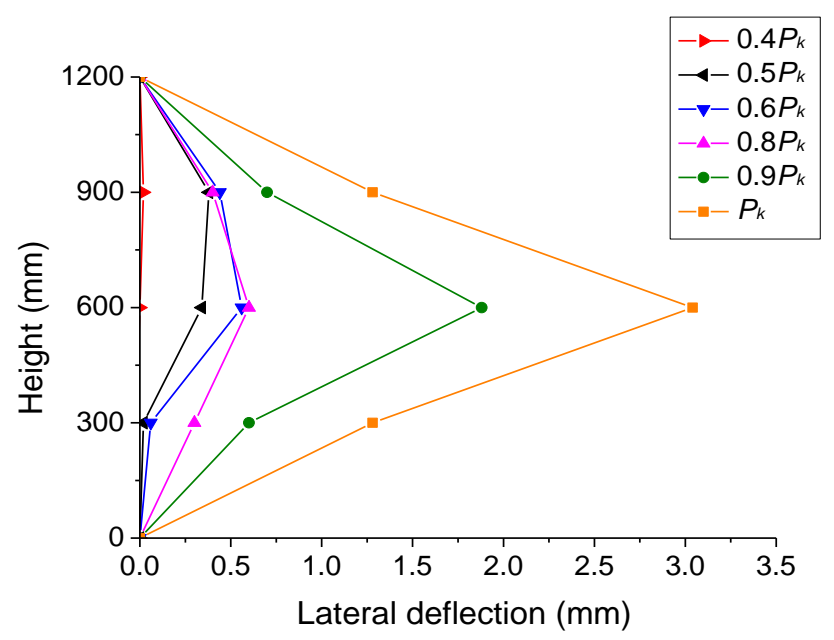

(a) Cw-0-1200

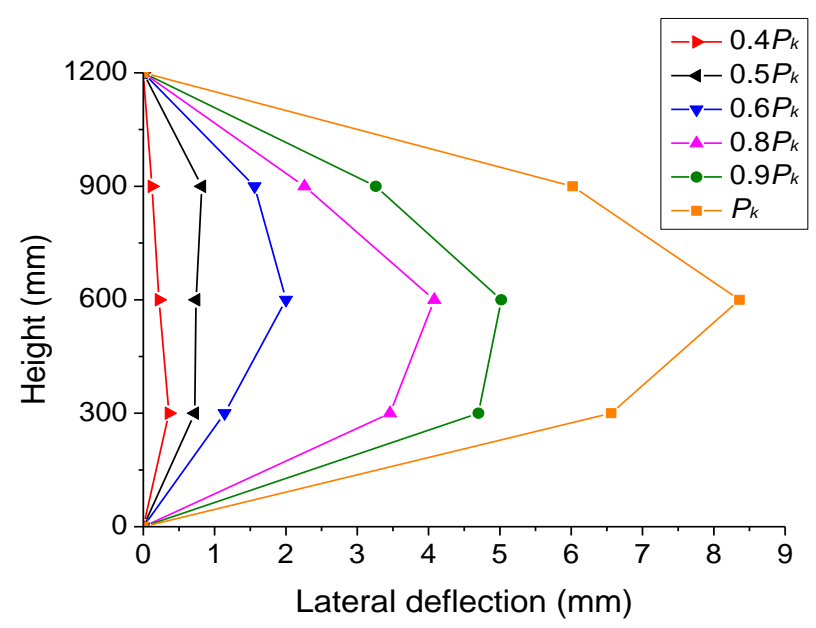

(c) $\mathrm{Cw}-50-1200$

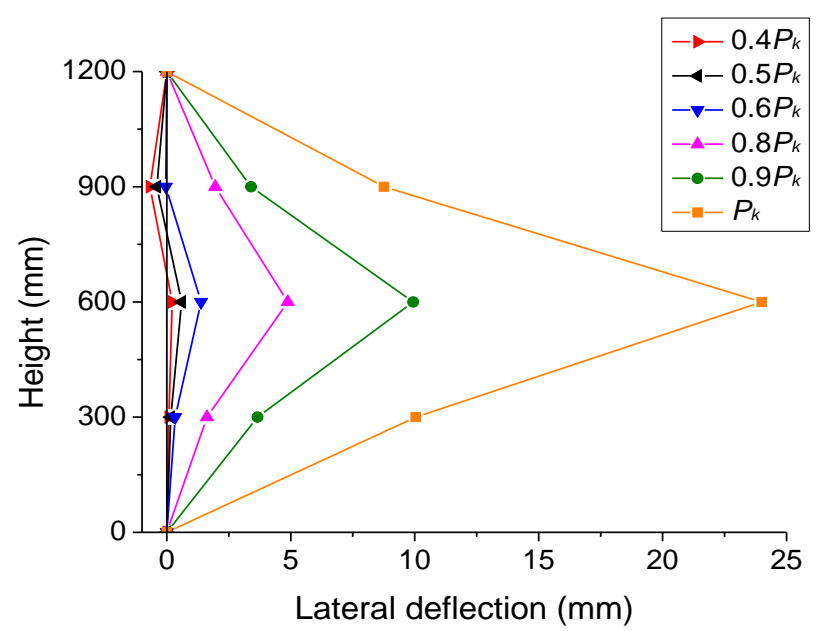

(e) $\mathrm{Cw}-100-1500$

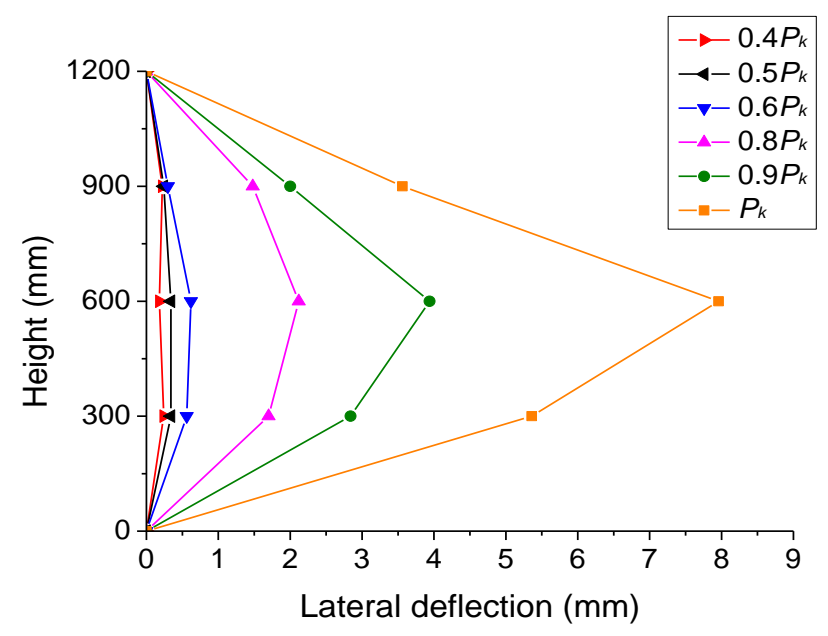

(b) $\mathrm{Cw}-30-1200$

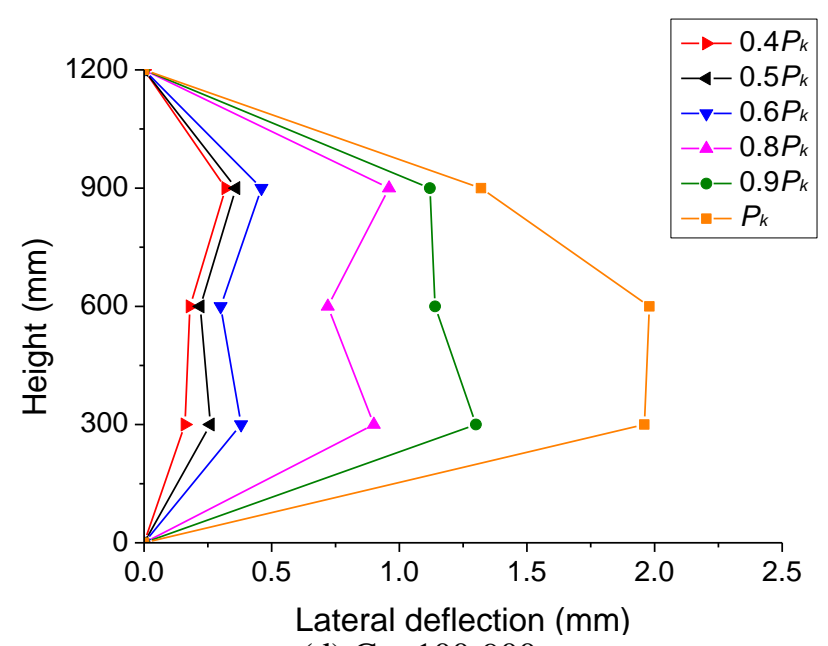

(d) $\mathrm{Cw}-100-900$

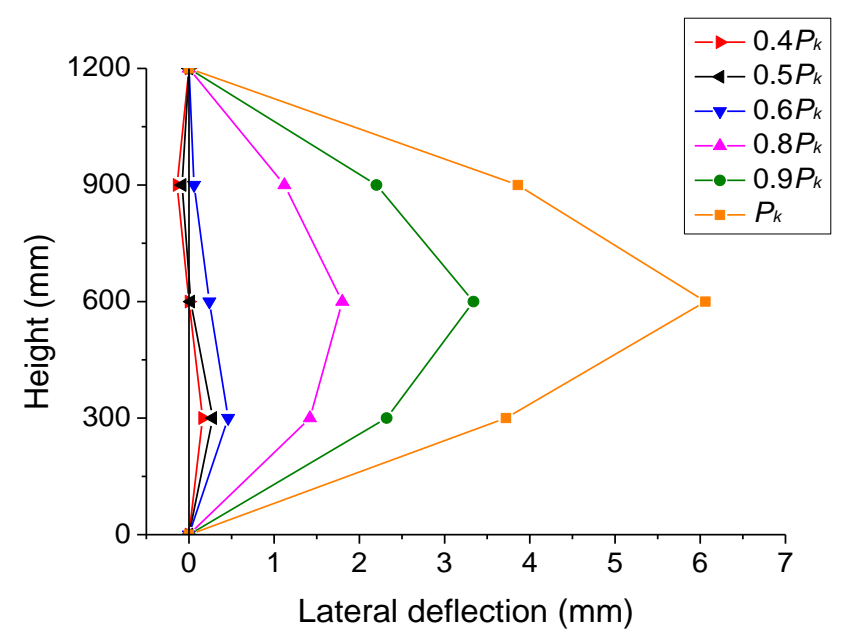

(f) $\mathrm{Co}-0-1200$

Fig.13 Lateral deflection curves at three cross-sections under different loads 


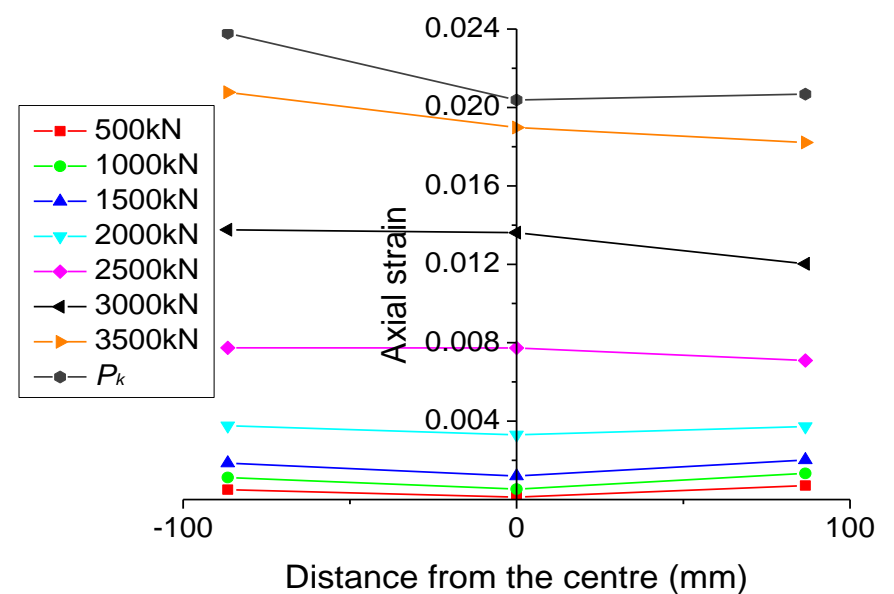

(a) Cw-100-1200 at Section B

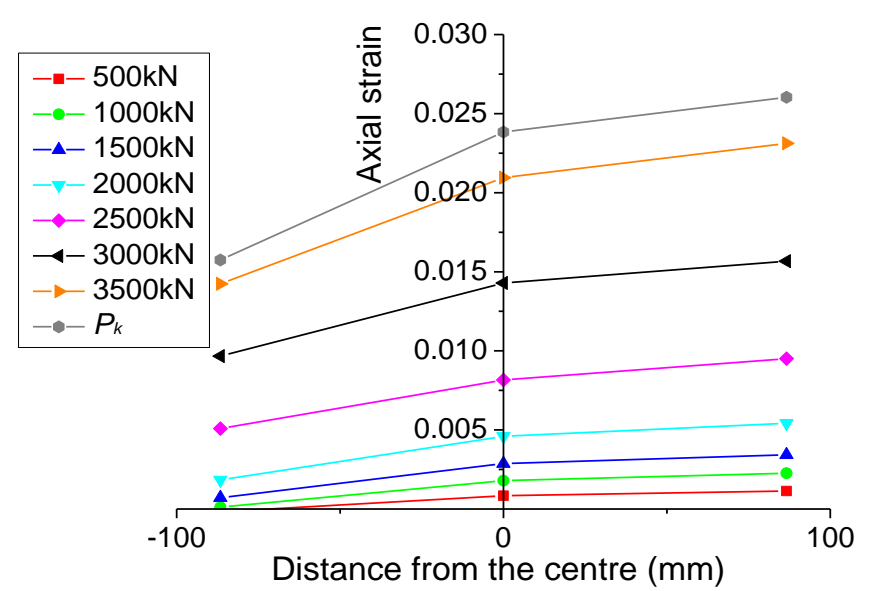

(c) Cw-100-1200 at Section C

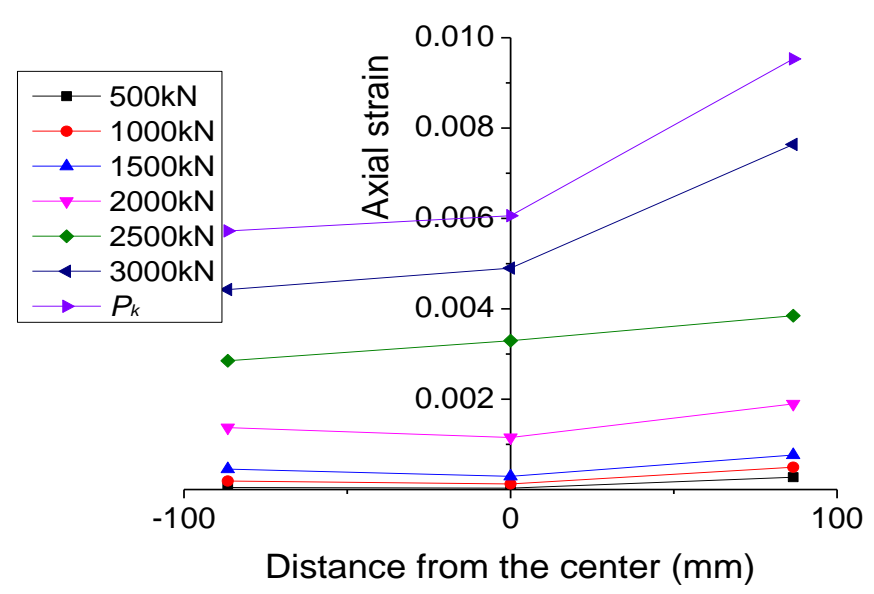

(e) Cw-100-1500 at Section C

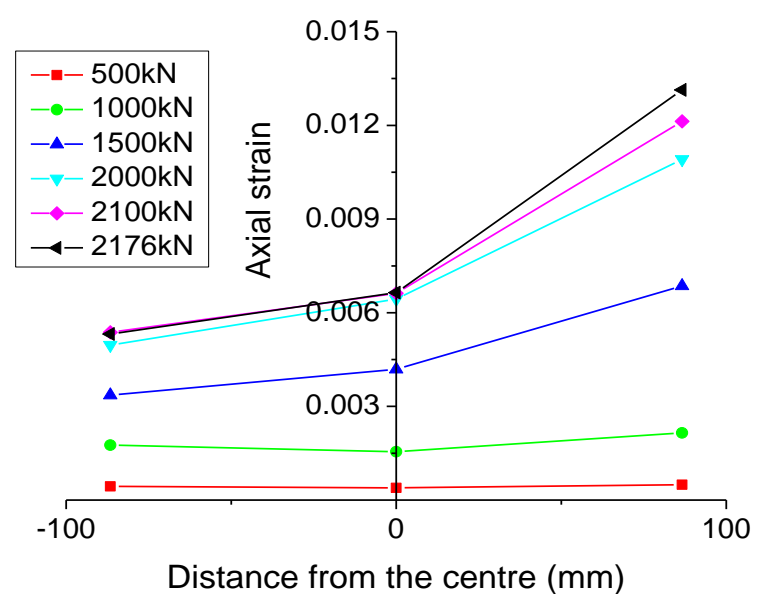

(b) Co-100-1200 at Section B

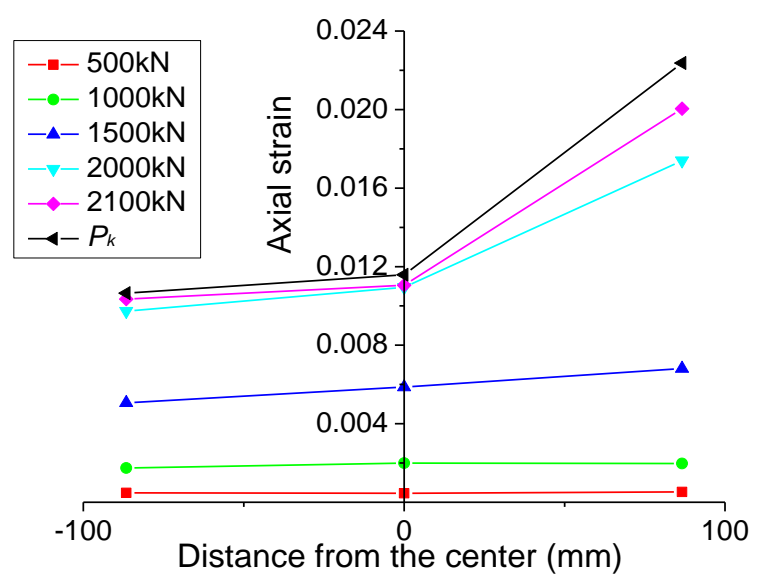

(d) Co-100-1200 at Section C

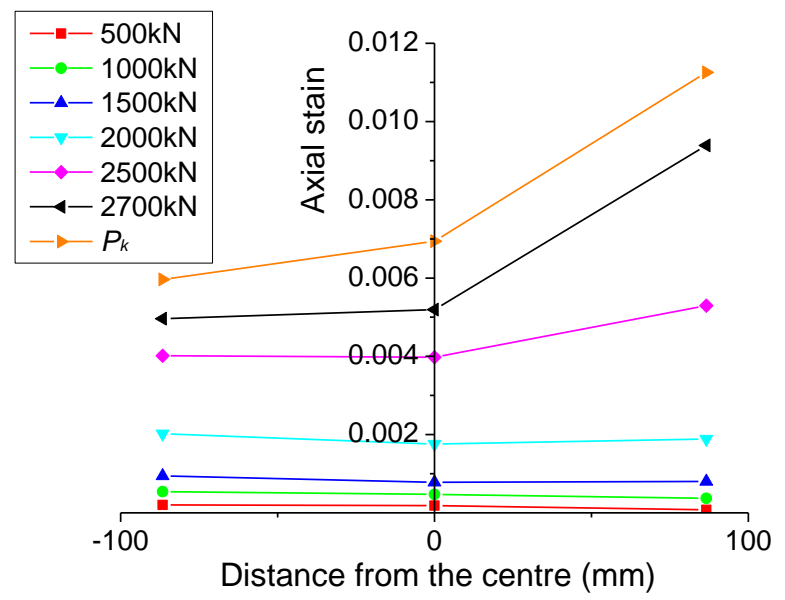

(f) Co-100-1500 at Section C

Fig. 14 Axial strains in GFRP tubes at cross-sections under different loads 


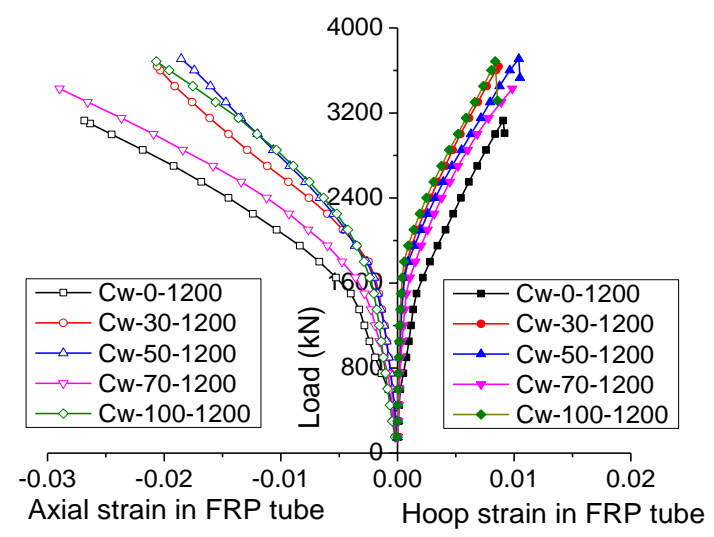

(a)

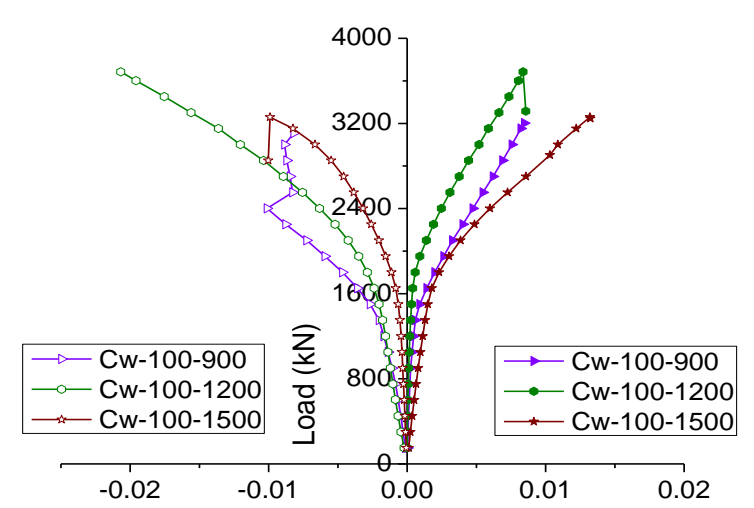

Axial strain in FRP tube Hoop strain in FRP tube

(c)

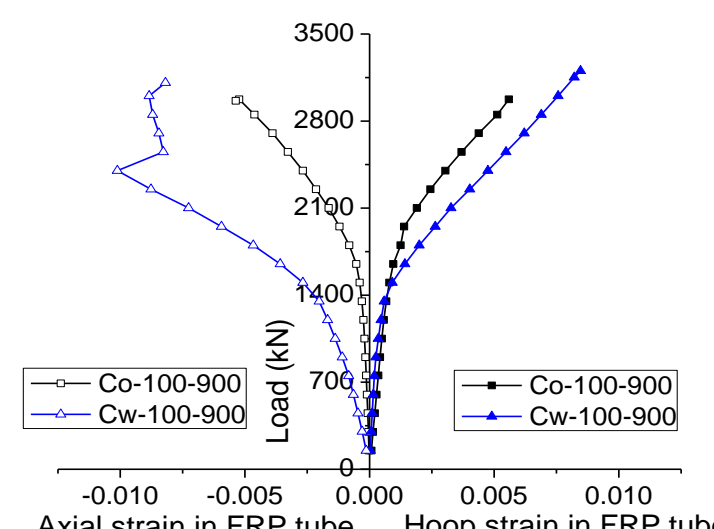

Axial strain in FRP tube Hoop strain in FRP tube

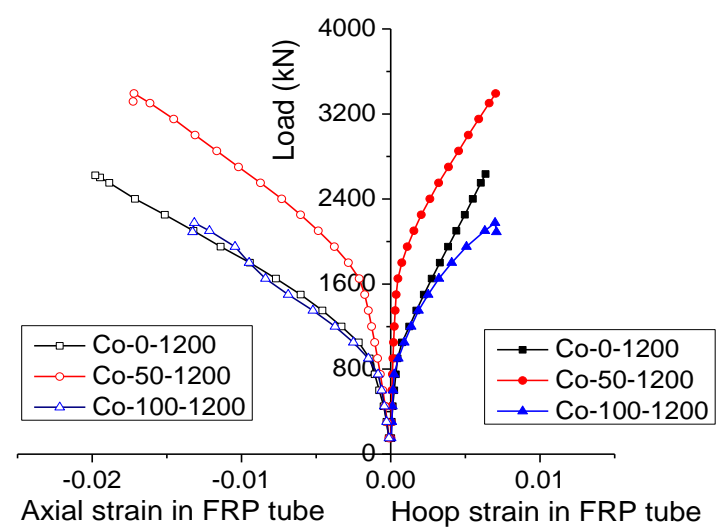

(b)

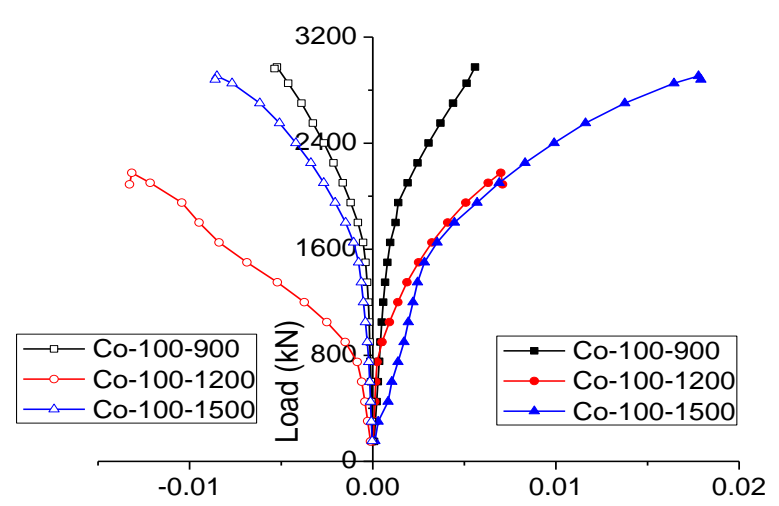

Axial strain in FRP tube Hoop strain in FRP tube

(d)

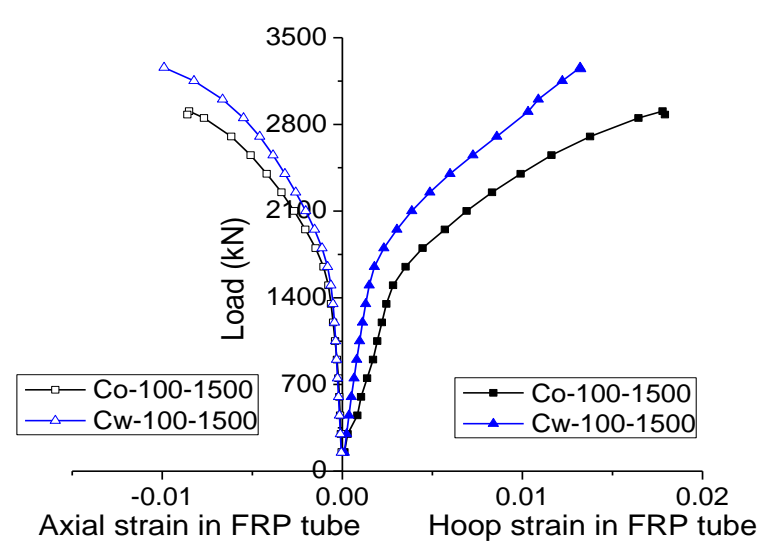

(f)

(e)

Fig. 15 Curves of load - mid-span strain in GFRP tubes 


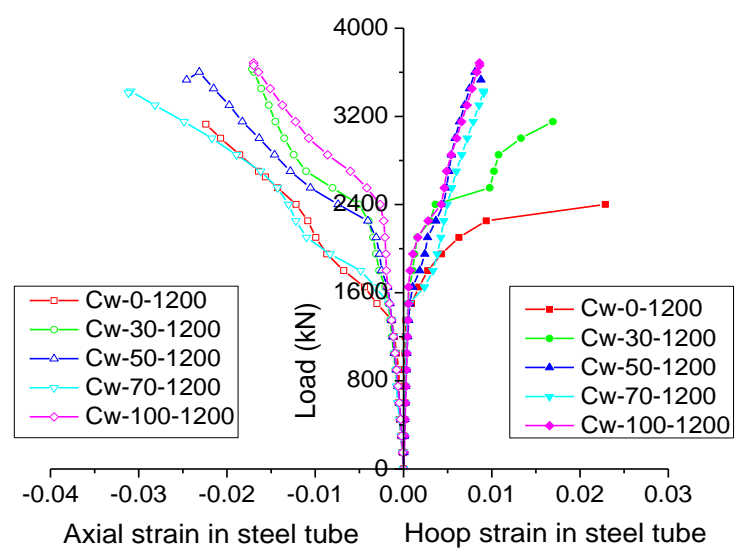

(a)

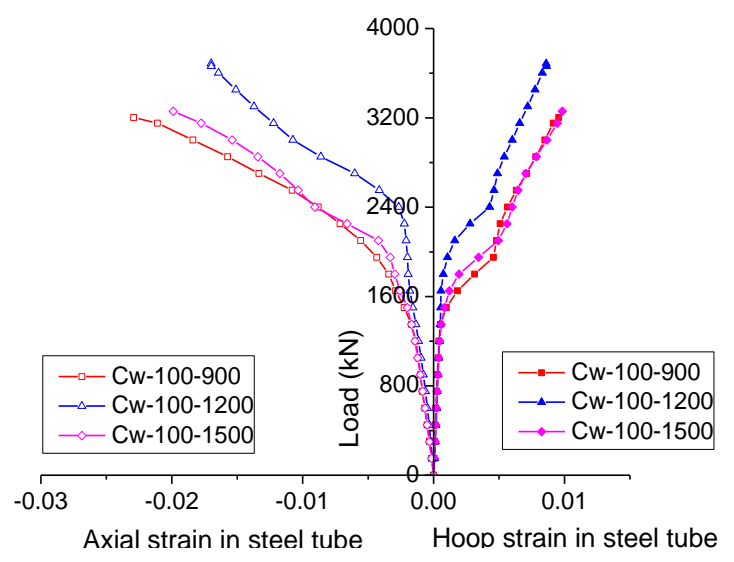

(c)

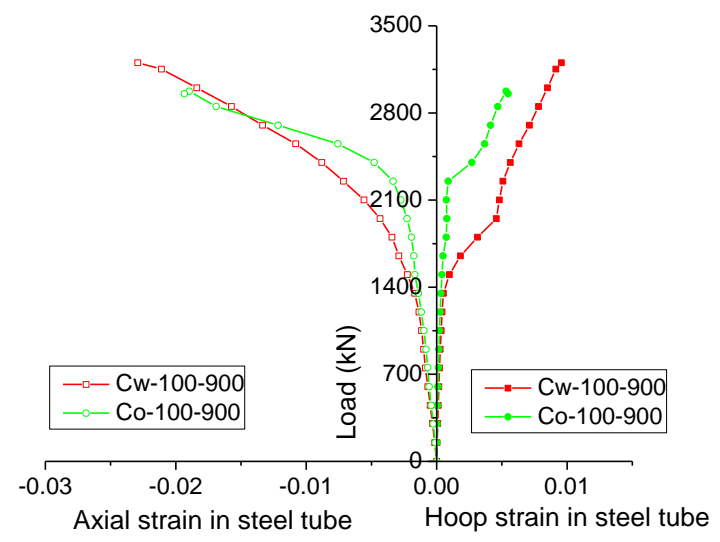

(e)

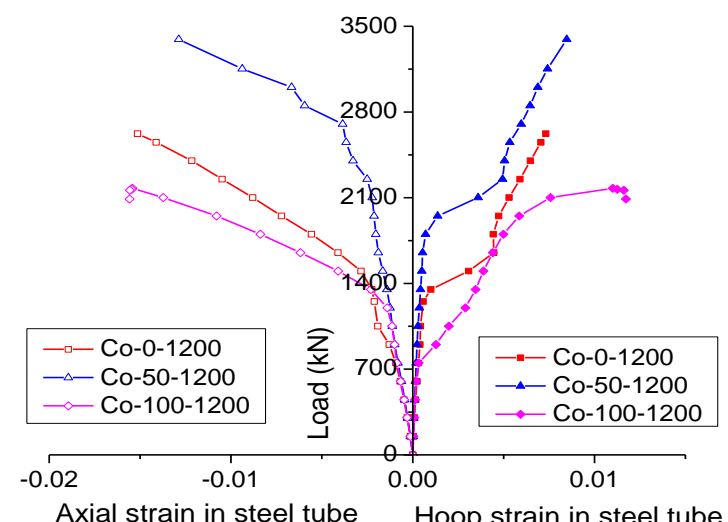

(b)

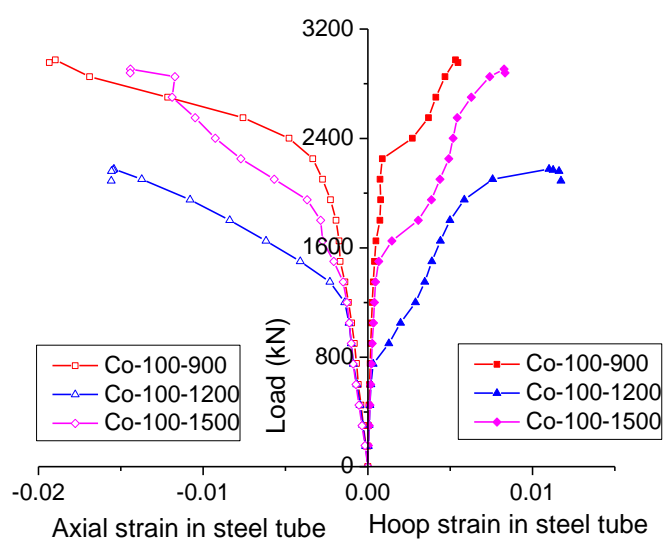

(d)

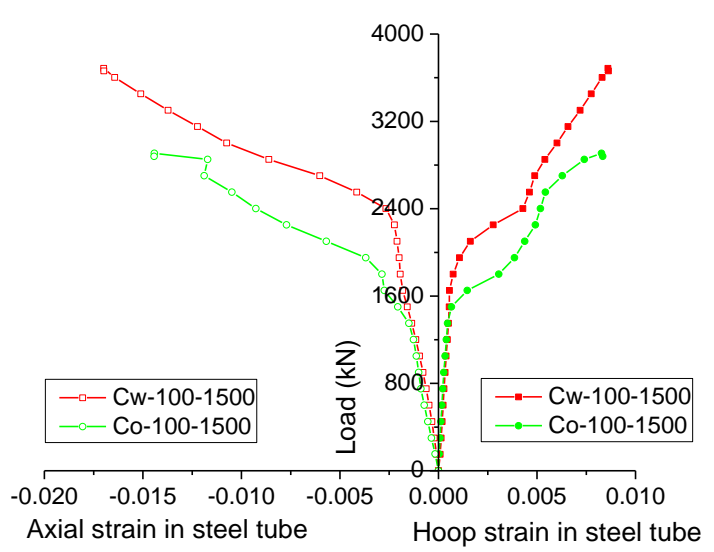

(f)

Fig. 16 Curves of load - mid-span strain in steel tubes 


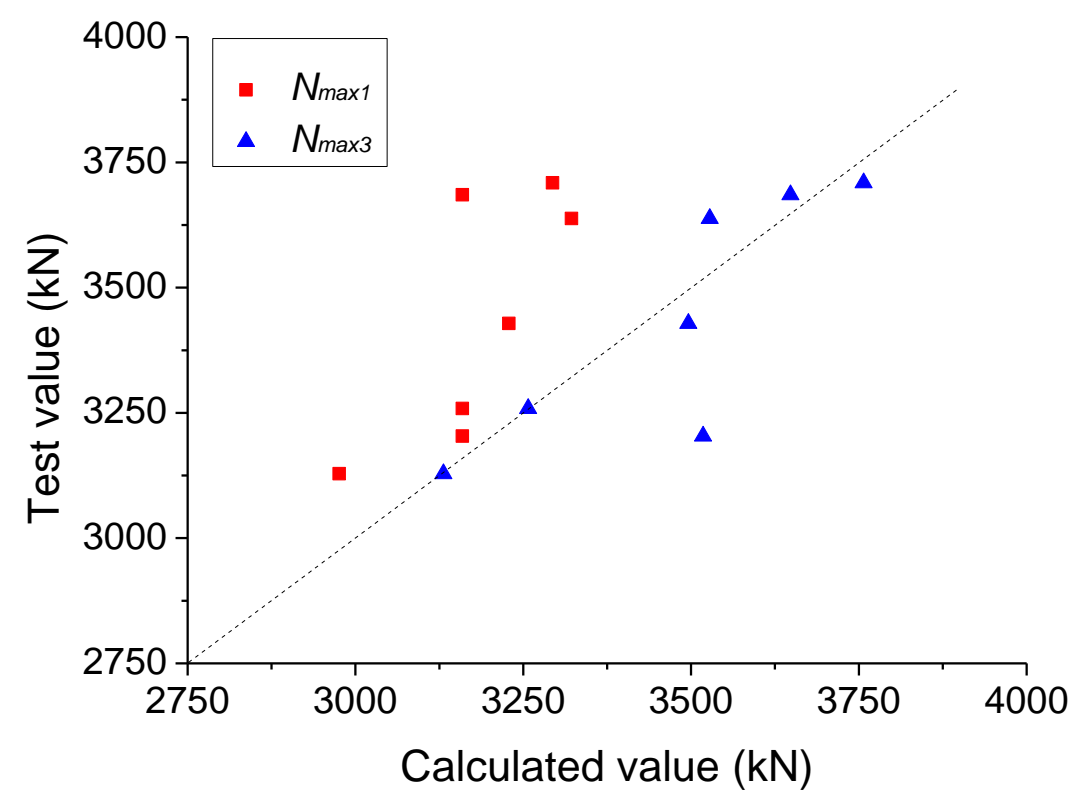

(a) whole area loading

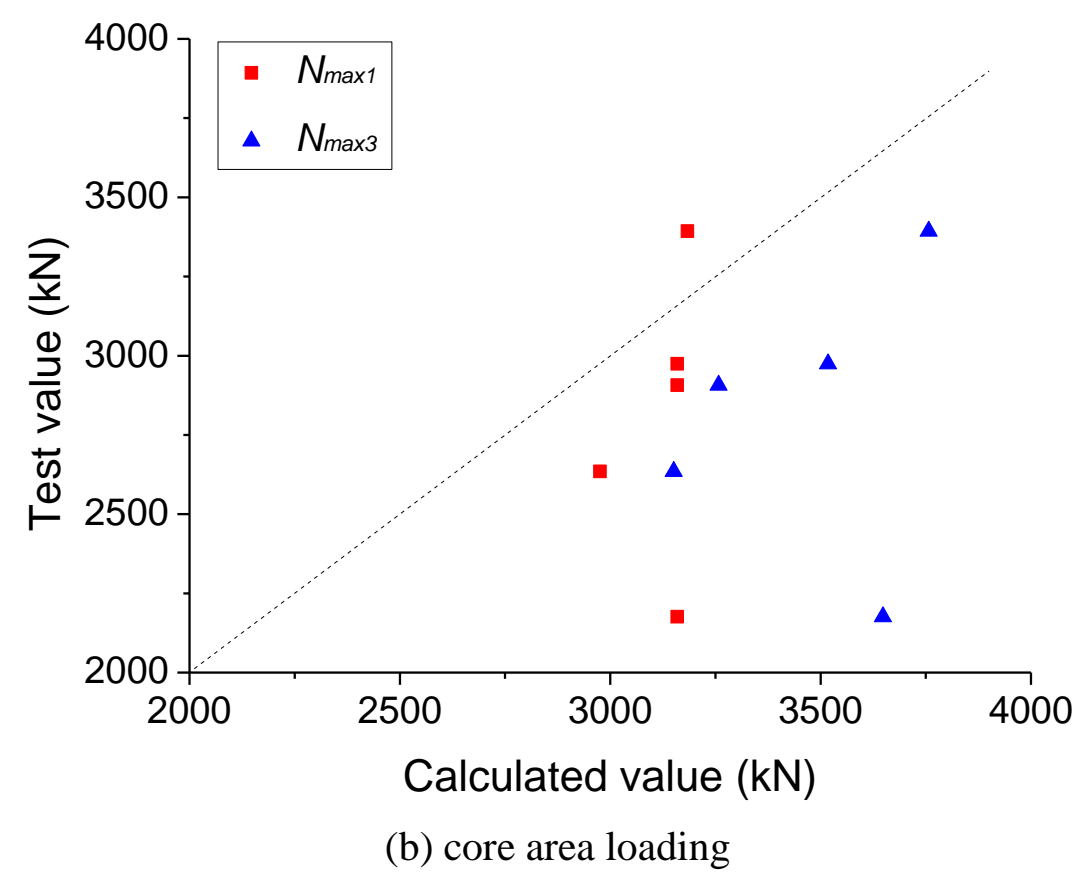

Fig.17 Contrast between test and calculated results of FRSLC specimens 